\title{
Residual Dentin Thickness of the Danger Zone in Mandibular Molar with Variable Sizes of Nickel-Titanium Rotary Instruments
}

Andrew Y. Xu

Follow this and additional works at: https://researchrepository.wvu.edu/etd

\section{Recommended Citation}

Xu, Andrew Y., "Residual Dentin Thickness of the Danger Zone in Mandibular Molar with Variable Sizes of Nickel-Titanium Rotary Instruments" (2015). Graduate Theses, Dissertations, and Problem Reports. 6987. https://researchrepository.wvu.edu/etd/6987

This Thesis is protected by copyright and/or related rights. It has been brought to you by the The Research Repository @ WVU with permission from the rights-holder(s). You are free to use this Thesis in any way that is permitted by the copyright and related rights legislation that applies to your use. For other uses you must obtain permission from the rights-holder(s) directly, unless additional rights are indicated by a Creative Commons license in the record and/ or on the work itself. This Thesis has been accepted for inclusion in WVU Graduate Theses, Dissertations, and Problem Reports collection by an authorized administrator of The Research Repository @ WVU. For more information, please contact researchrepository@mail.wvu.edu. 


\title{
Residual Dentin Thickness of the Danger Zone in Mandibular Molar with Variable Sizes of Nickel-Titanium Rotary Instruments
}

\author{
Andrew Y. Xu, D.D.S.
}

Thesis Submitted to the School of Dentistry of Robert C. Byrd Health Sciences Center at West Virginia University in partial fulfillment of the requirements for the degrees of

Masters of Science in Endodontics

Takashi Komabayashi, D.D.S., M.Dent.Sc., Ph.D. Chair

Anthony T. Borgia, D.D.S., M.H.A.

Michael D. Bagby, D.D.S., Ph.D., M.S.,

Department of Endodontics

Morgantown, West Virginia

2015

Keywords: Residual dental thickness, Nickel-Titanium, Danger zone, EndoSequence ${ }^{\circledR} \mathrm{NiTi}$ rotary instrument, mandibular mesial root, Microcomputed tomography (microcT) 


\title{
Abstract \\ Residual Dental Thickness of the Danger Zone in Mandibular Molar with Variable Sizes of Nickel-Titanium Rotary Instruments
}

\author{
Andrew Y. Xu, D.D.S.
}

\section{Introduction:}

Mechanical cleaning and shaping is an important component to the long term success of endodontic therapy. A larger diameter canal preparation allows for more penetration of antimicrobial solutions into the root canal system with resultant improved disinfection. The objective of this study was to determine the residual dentin thickness (RDT) of the distal wall of mandibular mesial roots after mechanical preparation by using $4 \%$ constant tapered NickelTitanium rotary (NTR) files with various tip sizes as evaluated utilizing microcomputed tomography (microCT).

\section{Methods:}

Twenty-five mandibular molars were mounted at the cemento-enamel junction (CEJ) in modified polypropylene $50 \mathrm{ml}$ centrifuge tubes using a non-radiopaque methyl methacrylate acrylic resin. All specimens were preoperatively scanned with microCT-40 (Scanco Medical, Switzerland). Images from the microCT-40 were transferred to Image ${ }^{\circledR}$ image analyzing software $(\mathrm{NIH}$, Bethesda, MD) to assess the initial dentin thickness of the distal wall measured $7 \mathrm{~mm}$ from the apices of the mandibular molar mesial roots. Canals were then instrumented to length with $4 \%$ tapered NTR files (EndoSequence ${ }^{\circledR}$ ) with varying apical sizes based upon group designation, either size 35.04, 40.04, 45.04, 50.04, 55.04. Each specimen was measured after canal preparation in a manner identical to the pre-instrumentation measurement using ImageJ $^{\circledR}$. Pearson correlation test was used to determine the correlation between preoperative mesiobuccal (MB) and mesio-lingual (ML) distal wall dentin thickness. The Kruskal-Wallis test was used to detect the amount of dentin that was removed and corresponding RDT among the five groups

\section{Results:}

Preoperatively, distal wall dentin thickness of $\mathrm{MB}$ and $\mathrm{ML}$ canals was found to be highly correlated (Correlation $=0.743$ ). A statistically significant difference was observed between the five groups with respect to dentin that was removed $(p=0.031)$ and the resulting RDT $(P=0.001)$. The median value of RDT for Groups A, Group B, Group C, and Group E were found to be close to $1 \mathrm{~mm}$ with the exception being Group $D(0.596 \mathrm{~mm})$.

\section{Conclusion:}

Root anatomy and preoperative dentin width thickness are the biggest factors that determine the amount of dentin removed by the files in the mid-root of the canal during mechanical root canal preparation. 


\section{Dedication}

To my father, XiaoDong Xu, my mother, Jun Lu: Thank you for the unconditioned love and ongoing support since the day I was born. I am so lucky to have you as my parents. You both are the best.

To my wife, Kristi Xu: Thank you for all these years you have stood behind me and supported me. There are no words to describe what a great wife and mother of our children you are.

To my children, Autumn, Macie, and Lydia: You are the best kids I can ask for. Thank you for being understanding when daddy has to do work. Daddy will always love you. 


\section{Acknowledgements}

Dr. Anthony Tom Borgia: Thank you for the last two years of mentorship. I enjoyed our conversations and friendship. I am so grateful you gave me a chance to be part of WVU family. Good luck with the Dean's position.

Dr. Keith Hildebrand: Thank you for all the clinical tricks you have shown me. I am glad you took the Chair position at WVU. I feel you will guide the WVU endodontic department in the right direction. I hope we can play golf together more often in the future.

Dr. Takashi Komabayashi: Thank you for sharing all your knowledge with me. You have helped me so much with my thesis project. Good luck with the new upcoming job.

Dr. Mark Byron: Thank you for spending every Friday coming to school to help the residents, students, and the department. I admire you doing this. Thank you for sharing clinical tricks and the business side with me.

Dr. Michael Bagby: Thank you for being part of my research committee member and help me on my thesis project

Dr. Jirun Sun: Thank you so much for allowing me to work with you at NIST and helping me scan these teeth.

Dr. Leann Long: Thank you for the statistical analysis. I very much enjoyed the conversations we had.

Dr. Yoshio Yahata: Thank you for helping me on my project. Good luck with everything in the U.S.

Dr. Pejman Parsa: I am so lucky to have you as not just being my co-resident, but also one of my best friends. For the past two years, we have pushed each other, learned from each other, and laughed together. This definitely made residency fun and exciting. Good luck with you in the future. Just remember I am always in Texas waiting for you.

Dr. Nathaniel Nicholson: I will never forget those snow days you picked me up with your truck. Thank you for showing me the West Virginia way. Thank you for allowing us to use your dad's clinic to work on my family members. I hope your golf game will continue to get better since you have a great teacher now. 
Dr. Khaled Seifelnasr: Thank you for sharing clinical knowledge with me and teaching me on how to drive in the snow. Thank you and your wife, Sumaya, for cooking authentic Egyptian food for me. It was delicious. Good luck with the new baby.

Dr. Emma Hunter: It was fun to talk to you about exercising and eating healthy foods. I think we are the best bodily fit residents in the nation. Too bad AAE doesn't have an award for that. Thank you for helping me edit my thesis and power point. Good luck being the new Chief.

Dr. Wisam Sakr: Thank you for allowing me to work with you and trusting my opinion. You have made tremendous improvement in this past year. Good luck next year. You are almost done.

Thank you to all the faculty and staff at WVU for supporting me and our Endodontic Department. 


\section{Table of Contents}

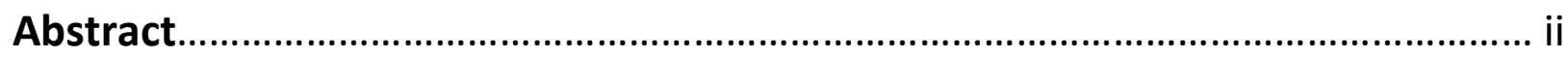

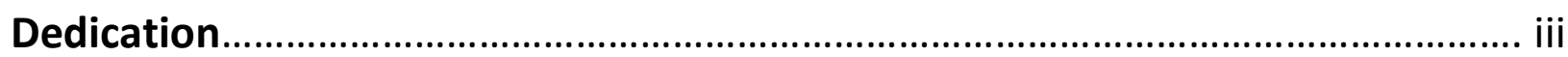

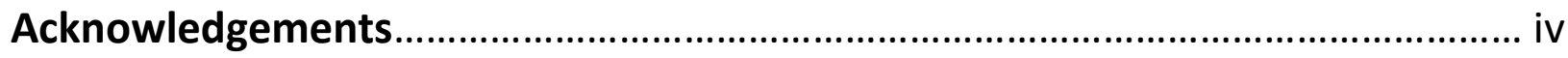

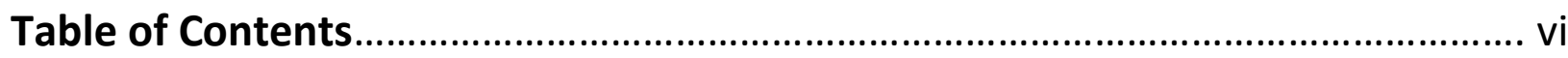

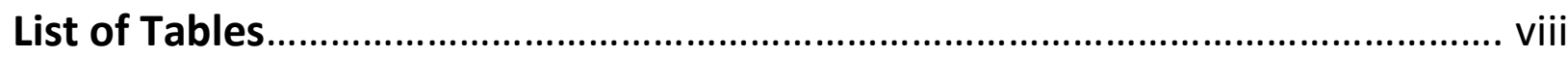

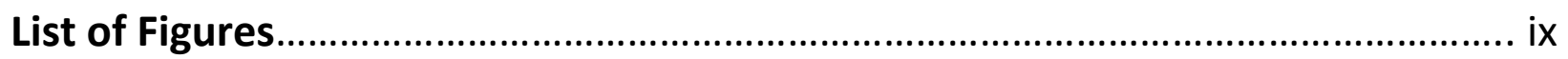

List of Symbols, Abbreviation, or Nomenclature ................................................. $\mathrm{x}$

\section{Chapter I:}

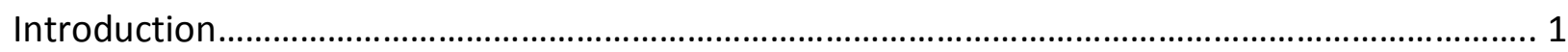

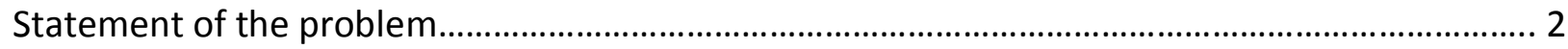

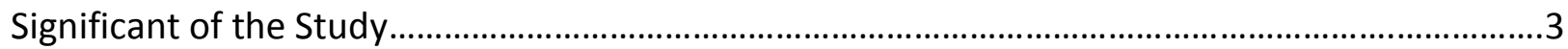

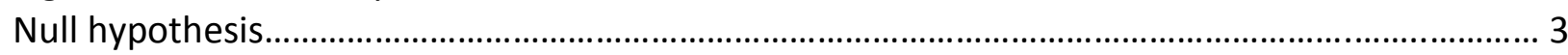

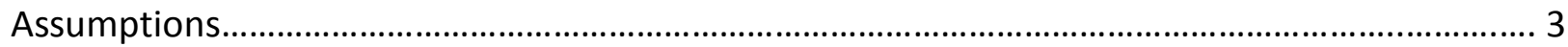

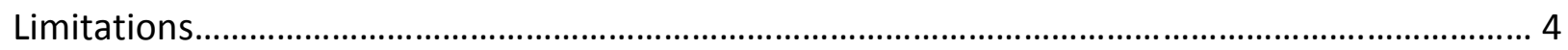

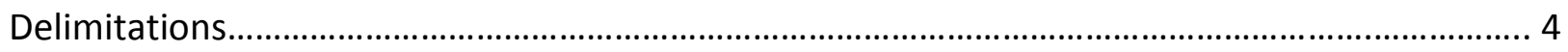

Questions to be answered.................................................................................................... 5

\section{Chapter II:}

Review of literature

\section{Chapter III:}

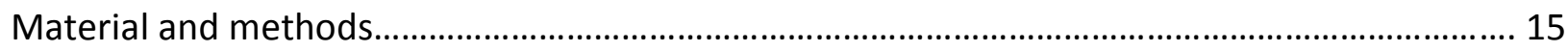

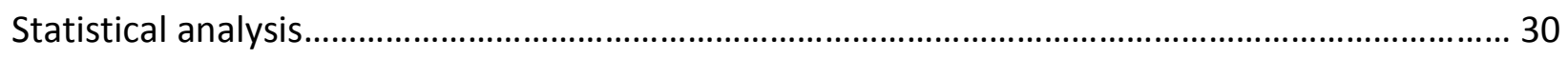

Chapter IV:

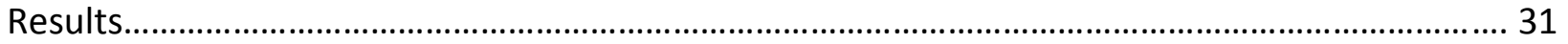

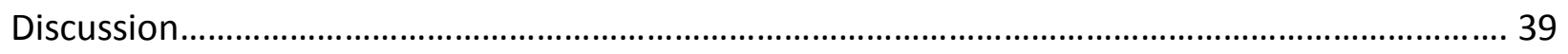

\section{Chapter V:}

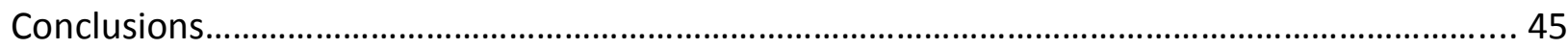

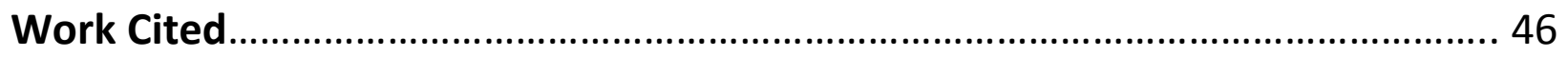




\section{Appendix}

Preoperative mandibular mesial root curvature measurements.................................................. 51

Preoperative root curvature measurements Group A................................................................ 52

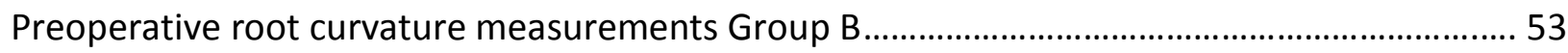

Preoperative root curvature measurements Group C............................................................... 54

Preoperative root curvature measurements Group D................................................................. 55

Preoperative root curvature measurements Group E.................................................................... 56

Institutional Review Board Exemption Approval Letter.......................................................... 57 


\section{List of Tables}

Table 1. Dentin thickness (preoperative) ................................................................................... 32

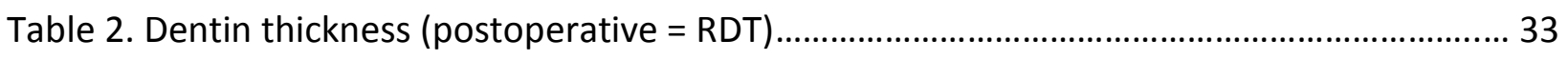

Table 3. Mean $(\mathrm{mm})$ and Median $(\mathrm{mm})$ of the distal wall dentin was removed by NTR

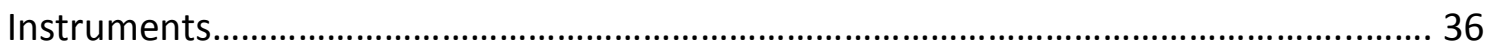

Table 4. Mean (mm) and Median (mm) of RDT by file size ....................................................... 38 


\section{List of Figures}

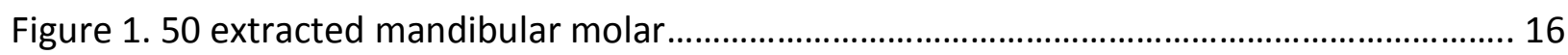

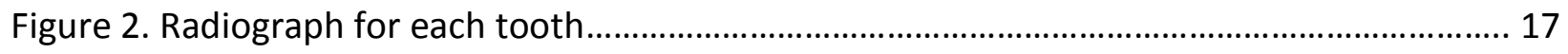

Figure 3. Specimen teeth were divided into 5 groups............................................................. 19

Figure 4. Non-radiopaque methyl methacrylate acrylic resin ................................................ 20

Figure 5. Tooth was mounted in the tube and buccal surface was marked............................... 21

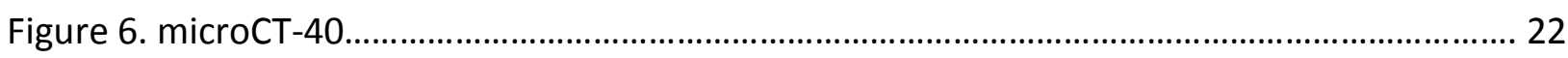

Figure 7. Method of measuring dentin thickness.................................................................... 23

Figure 8. Pre- and post-operative measurement images of Group A........................................ 25

Figure 9. Pre- and post-operative measurement images of Group B..................................... 26

Figure 10. Pre- and post-operative measurement images of Group C.................................... 27

Figure 11. Pre- and post-operative measurement images of Group D.................................... 28

Figure 12. Pre- and post-operative measurement images of Group E..................................... 29

Figure 13. Pearson correlation for preoperatively distal wall dentin thickness of MB and ML... 34

Figure 14. Comparison of the dentin was removed by each file size group............................... 35

Figure 15. Median $(\mathrm{mm})$ of the dentin was removed by Groups............................................... 36

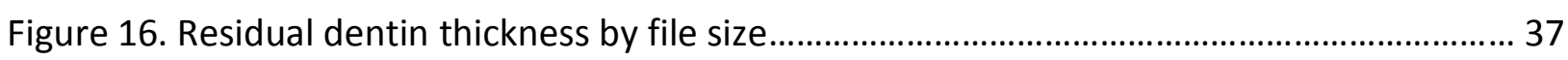

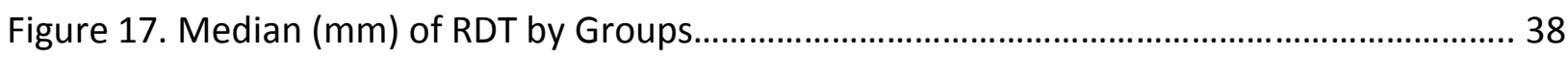




\section{List of Symbols, Abbreviation, or Nomenclature}

Nickel-Titanium rotary - NTR

Residual dentin thickness - RDT

Microcomputed tomography - microCT

Millimeters - $\mathrm{mm}$

Mesio-buccal - MB

Mesio-Lingual - ML

Sodium hypochlorite $-\mathrm{NaOCl}$

Ethylenediameteraacetic acid - EDTA

Chlorhexidine - $\mathrm{CHX}$

Working Length $-\mathrm{WL}$

Institutional Review Board - IRB

National Institute of Standards and Technology - NIST 


\section{Chapter I}

\section{Introduction}

It has long been known that the presence of bacteria in the pulp is the primary cause of periapical infection. ${ }^{1}$ Reduction of bacterial load in the root canal system plays a major role in determining the success of the endodontic therapy. ${ }^{2}$ In order to reduce the microbial load, chemo-mechanical preparation must be accomplished to ensure disinfection of the root canal system in order to achieve long term success of endodontic therapy. 3,4 A proper mechanically shaped root canal space enhances both the quality of the obturation and the disinfection of the root canal space. ${ }^{3}$ Numerous studies have shown that the larger the diameter of canal preparation, the more the volume of bacteria can be reduced ${ }^{4-12}$ as the result of allowing for more volume of antibacterial irrigant into the canal system to flush out debris and bacterial byproducts. ${ }^{13-15}$ However, there are surgical risks such as apical transportation, strip perforation, and instrument separation that can be involved when utilizing a larger apical preparation, particularly in curved and narrowed canal spaces. ${ }^{16}$

The mesial root of the mandibular molar is one of the most difficult roots to treat during endodontic procedures due to its acute inherent curvature in the middle root area. This is part of the so called danger zone, the area where the greatest narrowness of the diameter of the root, along with the distal surface concavity is located. ${ }^{17,18}$

The invention of the Nickel-Titanium rotary (NTR) instruments has greatly improved the quality of mechanical shaping. 5,19 These instruments not only increase the efficiency of preparation time, but also reduce clinical errors during mechanical shaping, and create less 
canal transportation when compared to stainless steel files. ${ }^{5,20,21}$ NTR instruments have now gained acceptance by the majority of clinicians for root canal therapy. ${ }^{19}$ Currently, the major commercially available NTR files are produced with both $4 \%$ and $6 \%$ constant tapers. These tapered files create a greater continually tapering root canal preparation as compared to conventional $2 \%$ tapered files, facilitating better root canal obturation. To the author's knowledge there are several studies on measurement of residual dentin thickness (RDT) after mechanical preparation with $2 \%$ tapered files. However, there are limited studies assessing the RDT of the distal walls of mandibular mesial roots as measured by microcomputed tomography (microCT) after canals have been shaped with $4 \%$ constant tapered NTR files, specifically when employing medium to large tip sizes.

\section{Statement of the Problem}

It is unknown what affect using a $4 \%$ constant tapered, medium to large sized tip NTR files would have on the dentinal integrity in the danger zone of mandibular mesial root canals. The objective of this study was to determine the median RDT of the distal walls of mandibular mesial roots measured in millimeters $(\mathrm{mm})$ after mechanical preparation using $4 \%$ constant tapered NTR files with various tip sizes as assessed by microCT. 


\section{Significance of the Study}

The results of this study will give clinicians a greater understanding of the margin of safety and the tendencies of various sized NTR instruments to compromise the structural integrity of mandibular molar mesial roots.

\section{Null Hypothesis}

There is no statistically significant difference in the residual dentin thickness at the midroot level of mandibular mesial roots when endodontically prepared with NTR files of sizes $35.04,40.04,45.04,50.04$, and 55.04 .

\section{Assumptions}

1) Mandibular mesial roots have a curvature in the mid-root section.

2) The danger zone is located in the distal wall of the mid-section of the mandibular mesial roots.

3) Mesio-buccal (MB) and mesio-lingual ( $\mathrm{ML}$ ) canals are similar in structure to each other.

4) Larger size apical enlargement reduces more dentin on the distal surface than the mesial surface in the mid-root section.

5) Larger size apical enlargement removes more dentin at the mid-root section than smaller apical preparation when using $4 \%$ constant tapered files.

6) Measurement by micro-CT is the most accurate way to determine dentin removal utilizing current technology. 


\section{Limitations}

1) This is an in-vitro study of a clinical procedure; therefore, the results may not correlate to an in vivo condition.

2) Small sample size.

3) Root canal anatomy can be widely varied from tooth to tooth.

4) Lengths of the roots are not standardized.

5) Diameters of the root canals can be varied, indicating that dentin thickness can be variable in each tooth as well.

6) Degree of curvature of the mesial canals can be varied.

\section{Delimitations}

1) Each tooth was examined radiographically preoperatively with mesial to distal and buccal to lingual views.

2) All roots selected preoperatively have curvatures between $11^{\circ}$ to $35^{\circ}$.

3) All teeth were accessed by one clinician in the same systematic approach utilizing identical methods, thereby keeping procedures as consistent as possible.

4) The use of microCT is a non-destructive way for measurement. 


\section{Question to be answered}

1) Are $M B$ and $M L$ canals similar to each other in regards to pre-instrumented dentin thickness?

2) Will any strip perforation occur using larger apical tip sized files in the danger zone?

3) Will there be enough post-instrumented dentin to maintain the integrity of the root structure?

4) What is the ideal apical size using $4 \%$ constant tapered NTR files for enlargement of the $\mathrm{MB}$ and $\mathrm{ML}$ canals? 


\section{Chapter II}

\section{Review of literature}

1. Anatomy of the mandibular mesial root and the danger zone

2. Apical enlargement to reduce bacterial load

3. Larger apical preparation to promote irrigant efficacy

4. The danger of strip perforation

5. Residual dentin thickness (RDT)

\section{Anatomy of the mandibular mesial root and the danger zone}

The morphology of mandibular molar canals has been extensively studied. The mesial canal has been described as one of the most difficult canals to treat. ${ }^{55}$ The danger zone is commonly referred to as the area of the distal wall of the mid-section of mandibular mesial root of mandibular molars. Root canals of these teeth are ribbon shaped and often located closer to the furcation than to the mesial surface, with the degree of the concavity being more on the distal wall than the mesial wall. Due to this unique shape of the root, a strip perforation can occur during root canal mechanical preparation in the distal wall much easier than in the mesial wall. ${ }^{17,22,23}$

It is universally accepted that a one dimensional view of the radiograph can often present insufficient information to the clinician to assess the complexity of the root canal system of mandibular molar mesial roots. Cunningham et al. ${ }^{24}$ selected 100 mandibular molars to evaluate the curvature of mesial roots. These teeth were radiographed and assessed with an 
endodontic hand file in place. The conclusion of the study was that $100 \%$ of mandibular mesial roots had curvatures that most complexity of the curvature cannot be determined by clinical radiographs, and that proximal view of the mesial root can exhibit greater curvature then the mesio-distal view. ${ }^{24}$

Berutti et al. ${ }^{22}$ measured the thickness of cementum/dentin in mesial roots of mandibular first molars. The teeth were fixed in a resin block and machine disc was used to slice the root in 90 sections immediately below the bifurcation. The sections were photographed by using stereomicroscope. The cementum/dentin thickness from the images was then measured and recorded. Berutti noted that the thickness of the cementum/dentin in the distal surface of the mesial mandibular root was less than that of the mesial surface of the root. Of note, $1.5 \mathrm{~mm}$ below the bifurcation was shown to have the least amount of dentin, approximately $1.2 \mathrm{~mm}$ to $1.3 \mathrm{~mm}$. This area has the greatest risk of strip perforation during instrumentation.

In a more recent work, Harris et al ${ }^{25}$ used microCT to investigate mandibular first molar mesial roots and concluded that the thinnest dentin is located at the inner curvature, about 1.5 $\mathrm{mm}$ below the furcation. The average minimum dentin thickness of the inner curvature of mesial roots was $1.28 \mathrm{~mm}$ at the furcation region. Harris recommended that the furcation of mesial roots should be considered the "danger zone" during endodontic procedures. 


\section{Apical enlargement to remove the bacterial load}

There is an extensive amount of evidence to suggest that a larger apical preparation is better for disinfection of the root canal system. Even though all bacteria cannot be completely eliminated, studies have shown that larger instrumentation is necessary to reduce bacterial volume. ${ }^{4,7-10}$ The canal diameter of the apical region of mandibular mesial roots is approximately $0.2-0.4 \mathrm{~mm}$, which suggests the apical region should be enlarged to a minimum ISO size $30 .{ }^{25,26}$ The most complexity of root anatomy is usually found in the apical region. A large apical preparation, then, can include more anatomical irregularities and remove greater bacterial volume. ${ }^{13}$

Rollison et al ${ }^{7}$ investigated the reduction of the bacterial volume after mechanically preparing the root canal with $4 \%$ tapered files as opposed to $2 \%$ tapered files. In the study, mesial mandibular roots were used and infected with Enterococcus faecalis. Half of the canals were mechanically shaped with GT Profile ${ }^{\circledR}$ files to apical size of 35.04 and the other half of the canals were shaped with Power- $\mathrm{R}^{\circledR}$ files to an apical size of 50.02 . The results of the study showed that the canals prepared with a size of 50.02 were more effective at removing bacteria load than the canals that were prepared with a size of 35.04. The study concluded that the larger apical size and not the size of the taper played a greater role in the reduction of bacterial volume.

Usman et al. ${ }^{11}$ investigated the efficacy of root canal debridement by using GT NTR files with tip sizes of 20 and 40 . After mechanical preparation of the canal, the apical third was sectioned at $0.5 \mathrm{~mm}, 1.5 \mathrm{~mm}$, and $2.5 \mathrm{~mm}$ and prepared for histological examination to assess 
the remaining debris. It was found that the size 20 left more debris in the apical third than the size 40. The conclusion was that the larger file had less debris remaining in the canal than the smaller preparation.

In a study by Siqueira, ${ }^{6}$ the reduction of bacterial population in the root canal was assessed after the canal system had been mechanically shaped with three different file systems and irrigated with sterile saline. It was found that Nitiflex file size 40 removed more bacterial than any of the other size files $(35,30)$ that were used, regardless of the percentage of the file taper. This study showed that larger apex preparation leads to a significant reduction in the amount of bacteria.

Tan et al. ${ }^{5}$ compared $\mathrm{K}$ hand files and NTR files (LightSpeed ${ }^{\circledR}$ ) on the effective removal of debris in the apical region of MB canals of mandibular molars. The study was divided into three groups: 1) Group 1 step-back with K file without coronal flaring; 2) Group 2 step-back with file with coronal flaring; and 3) Group 3 crown down with LightSpeed ${ }^{\circledR}$ with coronal flaring. The specimens were examined under a light microscope and canal cleanliness was assessed. The results showed that the large apical shaping with the LightSpeed ${ }^{\circledR}$ files demonstrated significantly cleaner canals than the hand file groups in the apical regions.

Card et al. ${ }^{12}$ showed undetectable bacteria after mandibular mesial canals were instrumented by $4 \%$ tapered size \#7 size Profile ${ }^{\circledR}$ Series $29^{\mathrm{TM}}$ file $(0.465 \mathrm{~mm})$ in $81.5 \%$ of the canals. Even further apical enlargement to size larger than $0.575 \mathrm{~mm}$ by LightSpeed $^{\circledR}, 89 \%$ of the canals showed no evidence of bacteria. This study supported the premise that large apical size reduces more bacteria than do those of smaller size. 


\section{Larger apical preparation to promote irrigant efficacy}

Numerous studies have shown that mechanical cleaning of the root canal system alone is ineffective in completely removing bacteria. ${ }^{4-7,11,12}$ By using a chemical antibacterial agent such as sodium hypochlorite $(\mathrm{NaOCl})$, ethylenediametetraacetic acid (EDTA), or chlorhexidine $(\mathrm{CHX})$ in conjunction with mechanical cleaning, there was a significantly improvement in disinfection of the canal system. This is essential for the success of endodontic therapy. ${ }^{8,27}$ Due to the complexity of root canal anatomy, there is currently no known antibacterial agent or irrigation device that can completely kill microorganisms in the canal system; therefore, adequate enlargement of the canal system allows for irrigation to become a critical step in achieving a high success rate for endodontic treatment. ${ }^{28,54}$

Chow ${ }^{29}$ studied the efficacy of irrigation in constructed glass tubes with internal diameter and taper similar to reamer files. The experiment was composed of two parts. The first part examined the apical extent of irrigation deposition in relation to needle depth penetration. Tube sizes of 50,60, and 70 were used. The second part of the experiment examined the relationship between the needle size and the effectiveness of irrigation. The results showed that the irrigant did not penetrate far beyond the tip of the needle. To facilitate removal of debris, the needle needs to be placed as close to the apex as possible without binding to the wall. Therefore, irrigation was more effective in large canals than in small canals.

Ram et al. ${ }^{13}$ studied the efficacy of irrigation by preparing roots to different apical sizes. In this study, single rooted human teeth were prepared to size 25,40 and 60 , respectively. A radiopaque solution was injected into each canal and verified radiographically. Each root was 
then irrigated with saline, and radiographs were then taken to assess the presence of the radiopaque solution. The finding of the study was that the irrigant was ineffective with a root apex prepared to a size 25 , while size 40 showed significant improvement, and size 60 had complete removal of the radiopaque solution. This study concluded that the diameter of the root canal at the apex is the most important factor in obtaining the maximum efficacy in root canal irrigation. The apex should be mechanically enlarged to a size 40 for to receive maximum benefits of the irrigant.

Falk et al. ${ }^{15}$ investigated the hypothesis that the efficacy of irrigation is dependent upon the size of the apical preparation. Thirty permanent canine teeth were prepared to apical sizes of 36,60 and 70 by using $4 \%$ tapered Profile ${ }^{\circledR}$, Series $29^{\mathrm{TM}}$ files. Canal spaces were first sterilized and then infected with bacteria. Next, $6 \mathrm{ml}$ of sterile distilled water was delivered with a 28 gauge endodontic needle placed $1 \mathrm{~mm}$ from the working length. The results were that sizes 60 and 70 showed significantly reduced bacterial volume as compared to size 36 . There was no statistical difference between the canals instrumented to a size 60 or 70 . The conclusion was that larger apical sizes can increase efficacy of the irrigant. An enlargement beyond size 60 did not further reduce bacterial volume in the canal, since $10 \%$ of bacteria still remained in the canal system after irrigation.

Brunson et al. ${ }^{14}$ studied the effect of apical preparation size and taper on irrigant volume delivered. The study included 40 human single rooted teeth, and was divided into two phases. In the first phase, all samples were prepared with 6\% taper and differing tip sizes, ranging from size 30 to 45 . In the second phase, canals were prepared using the same tip size, but with different taper, ranging from $2 \%$ tapered to $8 \%$ tapered files. All samples were 
irrigated with a negative pressure micro-cannula with $\mathrm{NaOCl}$ at $\mathrm{WL}$ for 30 seconds. Irrigant was collected and the volume was measured. The results were a $44 \%$ increase in volume of irrigant delivered when increasing apical diameter from ISO size 35 to 40 . A change from ISO size 40 to 45 resulted in a $4 \%$ increase in volume. When comparing the taper size, a canal enlargement from 40.02 to 40.04 , had a $74 \%$ irrigant volume increase; 40.04 to 40.06 had a $5.4 \%$ irrigant volume increase; 40.06 to a 40.08 had $2.4 \%$ volume increase. This study concluded that apical preparation should be enlarged to an ISO size 35 to 40 with a $4 \%$ tapered file. Such sizes are well balanced between the volumes of the irrigant introduced to the canal, while maintaining the integrity of the root structure.

\section{The danger of strip perforation}

Strip perforation is an iatrogenic occurrence. ${ }^{30,31}$ Thinning dentin thickness and strip perforation happen during the negotiation of curved canals or by over enlarging the canal space. A strip perforation creates an artificial communication between the canal space and the surrounding supporting tissue. ${ }^{17}$ The flared canal preparation can help to facilitate more effective cleaning and shaping of the canal, can reduce the breakage of endodontic files, and also facilitates better obturation of the canal space. ${ }^{3}$ However, strip perforation is a potential risk of enlarging the canal space, especially in the mid-root region of the mandibular mesial root where the canal space is curved. ${ }^{17,18}$ Several studies have shown that root perforation occurs approximately $2-12 \%$ during endodontic treatment. ${ }^{32-37}$ 
Lim and Stock ${ }^{23}$ evaluated perforation tendencies of two different filing techniques, anti-curvature and step-back filing, in mandibular mesial roots of 30 extracted teeth. The authors found that the area most prone to perforation was at a level of $8 \mathrm{~mm}$ from the apex on the distal wall of the mesial root. The RDT of roots with moderate curvature and those with severe curvature were not significantly different; therefore, there was no correlation between the curvature of the root and the risk of strip perforation.

\section{Residual dental thickness (RDT)}

There has been an ongoing clinical dilemma between the importance of adequate apical enlargement for removing bacteria and necrotic tissue and the necessity of preserving the integrity of root structure. ${ }^{38}$ Many studies have recommended that the root canal space in the coronal segment should not exceed one third of the root diameter in all levels to preserve its

mechanical integrity. ${ }^{39-41,57}$ It has also been recommended that a minimum of $1 \mathrm{~mm}$ circumference of RDT should be maintained, as to not jeopardize root structure integrity. ${ }^{42,43,56}$

Zuckerman et al ${ }^{38}$ measured the RDT after mandibular mesial root canals were enlarged with LightSpeed ${ }^{\circledR}$ endodontic files. In his experiment, 30 mandibular mesial roots were initially horizontally sectioned at 1,4 , and $7 \mathrm{~mm}$ from the apex. The dentin was measured in mesial, distal, buccal and lingual directions. The roots were re-assembled and the coronal third of the canals was flared with a Gates-Glidden \#2 and enlarged with LightSpeed ${ }^{\circledR}$ to a size 50 file. The three sections were disassembled and measured. The RDT after instrumentation at levels of $1 \mathrm{~mm}, 4 \mathrm{~mm}$, and $7 \mathrm{~mm}$ was $0.7 \mathrm{~mm}, 1.04 \mathrm{~mm}$ and $1.09 \mathrm{~mm}$. None of the canals exceed one 
third of the root diameter. Zuckerman concluded that canal space enlarged to a size 50 LightSpeed $^{\circledast}$ file did not significantly reduce the RDT.

As mentioned in the strip perforation section, Lim et al ${ }^{23}$ also measured RDT of the mesial roots of mandibular molar teeth after these teeth were prepared with two different filing techniques. The RDT of the distal wall at $8 \mathrm{~mm}$ was between $0.56-0.59 \mathrm{~mm}$ and $0.72-0.80$ $\mathrm{mm}$ were at $5 \mathrm{~mm}$. The distal wall of the mandibular mesial root showed significantly more dentin being removed at $8 \mathrm{~mm}$ compared to the $5 \mathrm{~mm}$ from apex.

In a recent publication by Junior et al., ${ }^{44}$ two NTR file systems, Mtwo and Reciprroc NiTi, were compared and evaluated on their removal of dentin in the danger zone of mandibular molars. Original measurements were taken with microCT of twelve mesial mandibular roots. The canal spaces were then mechanically prepared by Mtwo to 40.04 and Reciproc NiTi file systems to 40.06 . Root canal volume and dentin thickness at different levels were measured and analyzed. The results showed that the two NTR file systems did not remove a significant amount of dentin, as compared to the original measurement, validating the overall safety of a larger apical preparation. 


\section{Chapter III}

\section{Material and methods}

The application and approval for the Institutional Review Board (IRB) was applied for and obtained at West Virginia University. The IRB protocol tracking number is 1406315761 (Appendix page 57).

Fifty extracted de-identified first and second human mandibular molars were obtained according to protocols approved by the Institutional Review Board (IRB) of West Virginia University. The teeth were each marked with sample numbers for identification and preserved in a normal saline solution (Figure 1). A dental hygiene student performed scaling and root planning to remove gross calculus and plaque from these teeth. 

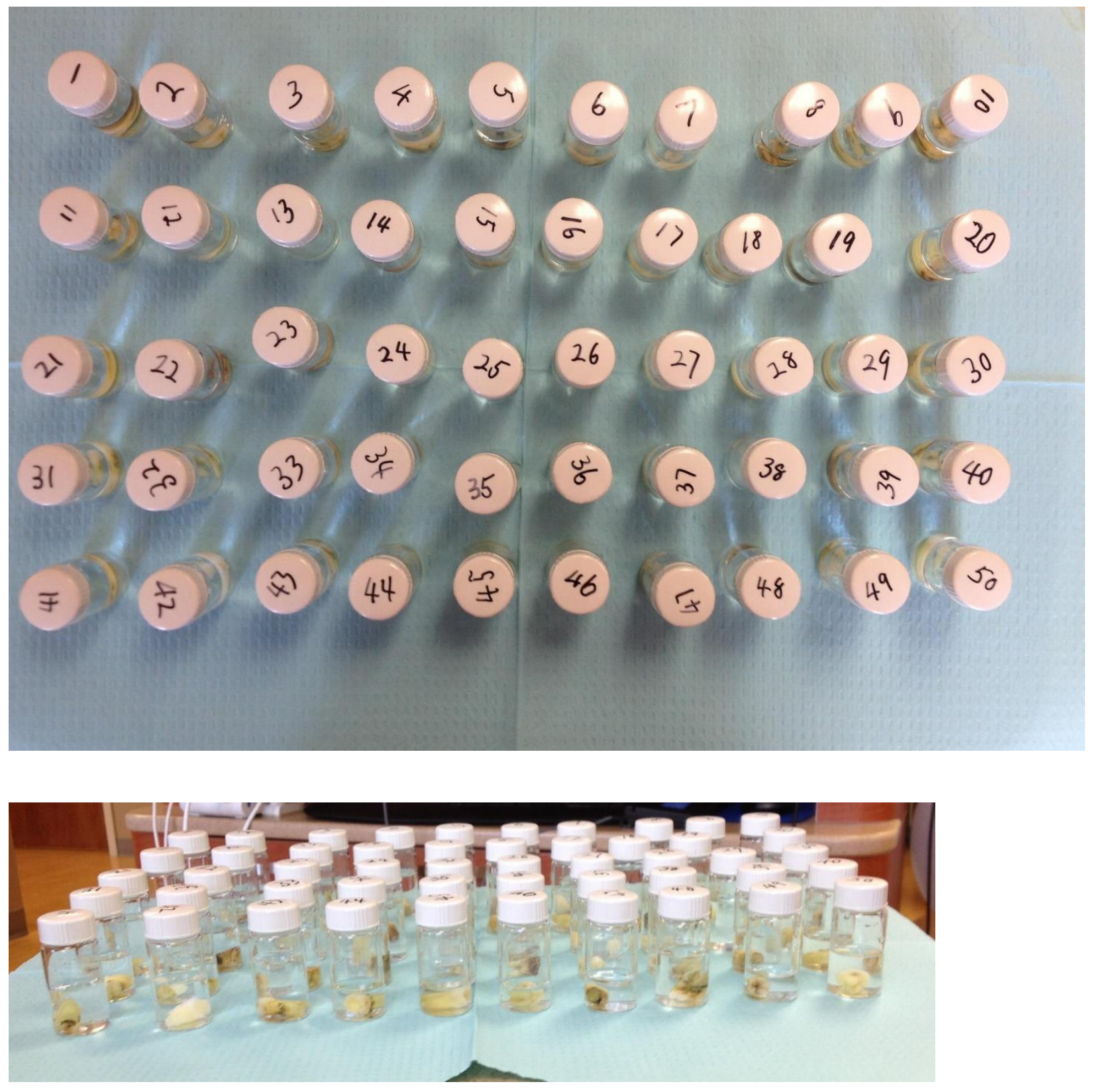

Figure 1. 50 extracted mandibular molars 
The cleaned teeth were secured with utility wax to the center of a digital sensor (Kodak RVG 6100; Carestream Health, Rochester, NY). Radiographic images were taken with the X-ray tube in a fixed position (Figure 2), and exposures were made in the bucco-lingual and mesiodistal planes of each tooth. The images were recorded in MiPACS imaging software (Medicor Imaging, Charlotte, NC, USA).

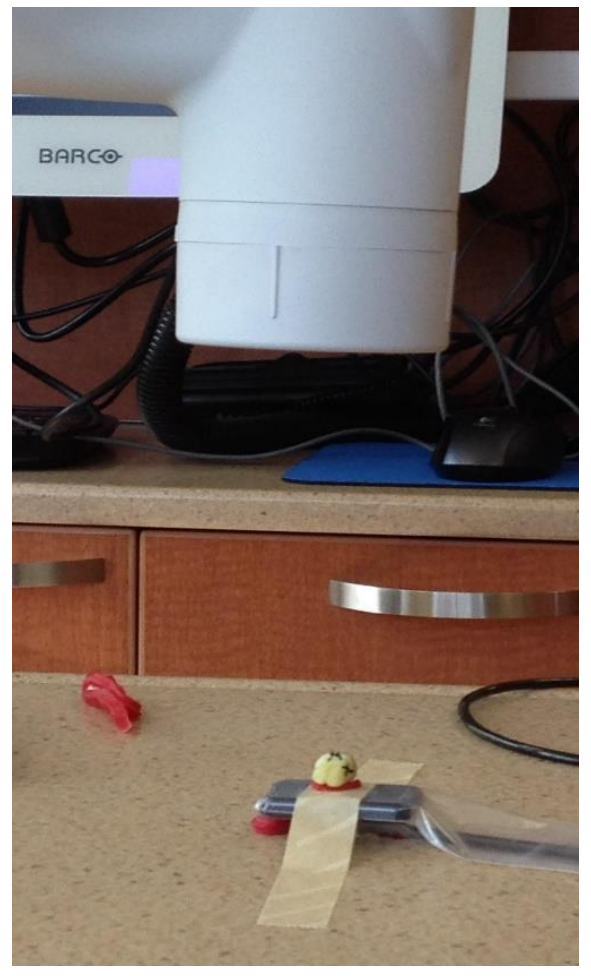

Figure 2. Radiograph for each tooth 
The radiographs were examined to ensure that all mandibular root canals were visible radiographically. At the completion of the assessment, $25(\mathrm{~N}=25)$ of the 50 mandibular molars were chosen for inclusion in the study. The mean curvature of the MB and ML roots was $20.4^{\circ}$ (Range: $11^{\circ}$ to $35^{\circ}$ ). The calculation of root curvature has been described by Schneider ${ }^{45}$ as a line drawn parallel to the long axis of the root canal and a second line drawn from the apical foramen to intersect with the first line at the outermost point of the canal (Appendix page 52 56). The teeth were randomly divided into five different groups: Group A (35.04), B (40.04), C (45.04), D (50.04), and E (55.04), with five teeth included in each group (Figure 3). 


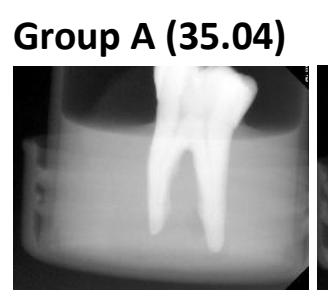

A1

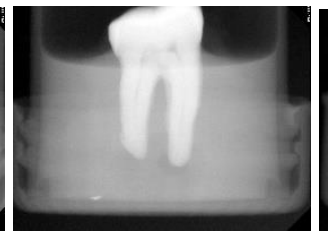

A2

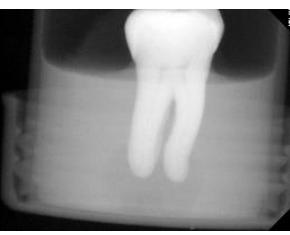

A3

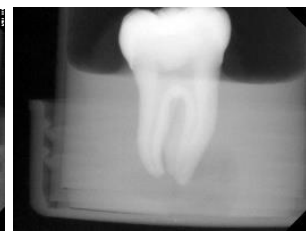

A4

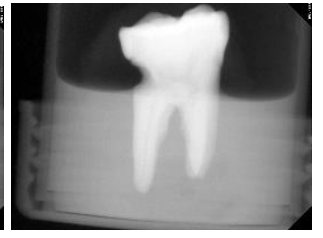

A5

Group B (40.04)

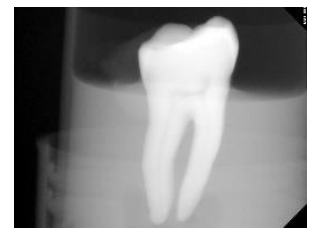

B1

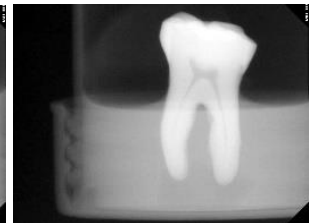

B2

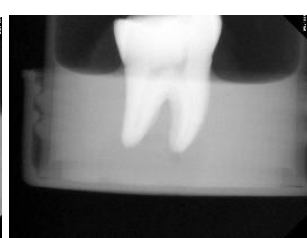

B3

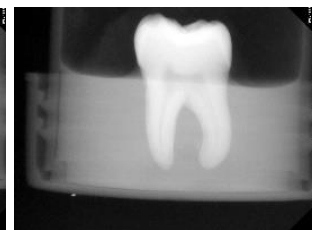

B4

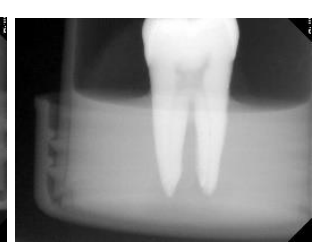

B5

\section{Group C (45.04)}

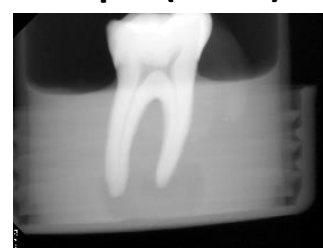

C1

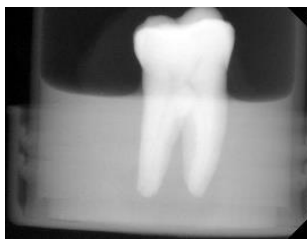

C2

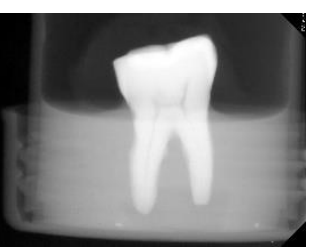

C3

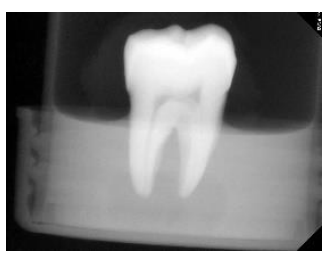

C4

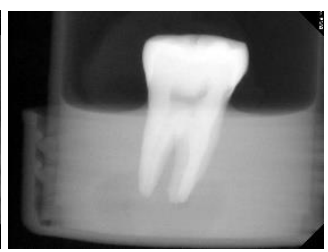

C5

\section{Group D (50.04)}

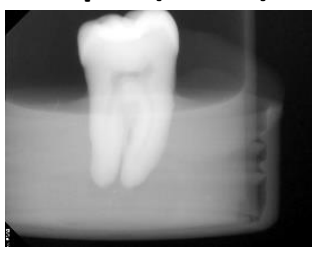

D1

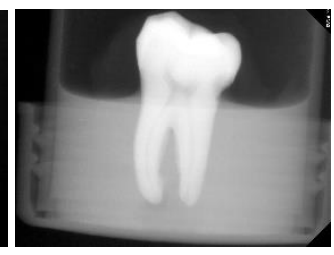

D2

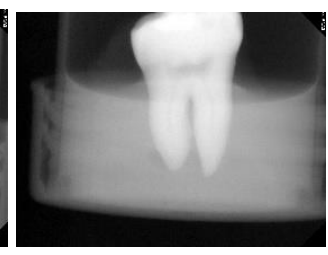

D3

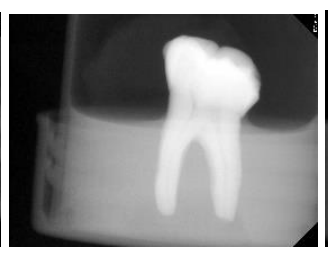

D4

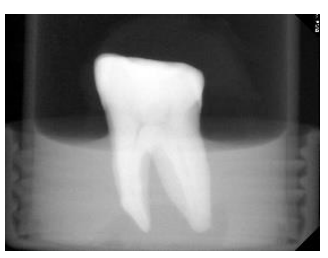

D5

\section{Group E (55.04)}

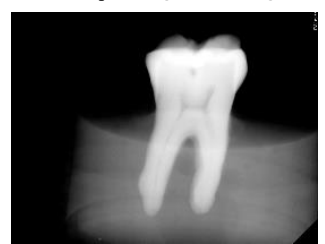

E1

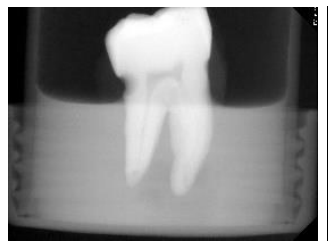

E2

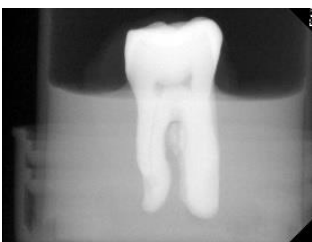

E3

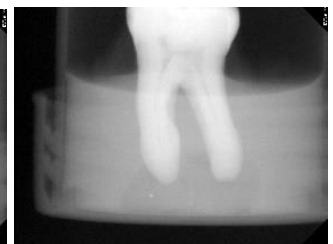

E4

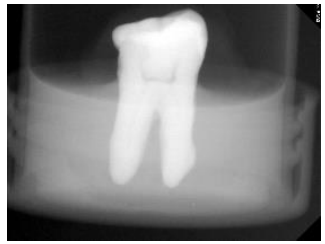

E5

Figure 3. Specimen teeth were divided into 5 groups $(\mathrm{N}=25)$ 
The specimen teeth were mounted at the cemento-enamel junction (CEJ) in modified polypropylene $50-\mathrm{ml}$ centrifuge tubes (Thermo Fisher Scientific, Waltham, MA) using a nonradiopaque methyl methacrylate acrylic resin (Varidur ${ }^{\circ}$ Buehler LTD, Lake Bluff, IL) (Figure 4). Each tooth was embedded upright in one centrifuge tube. The facial and mesial surfaces of each tooth were marked for scanning purposes to ensure operator consistency (Figure 5).

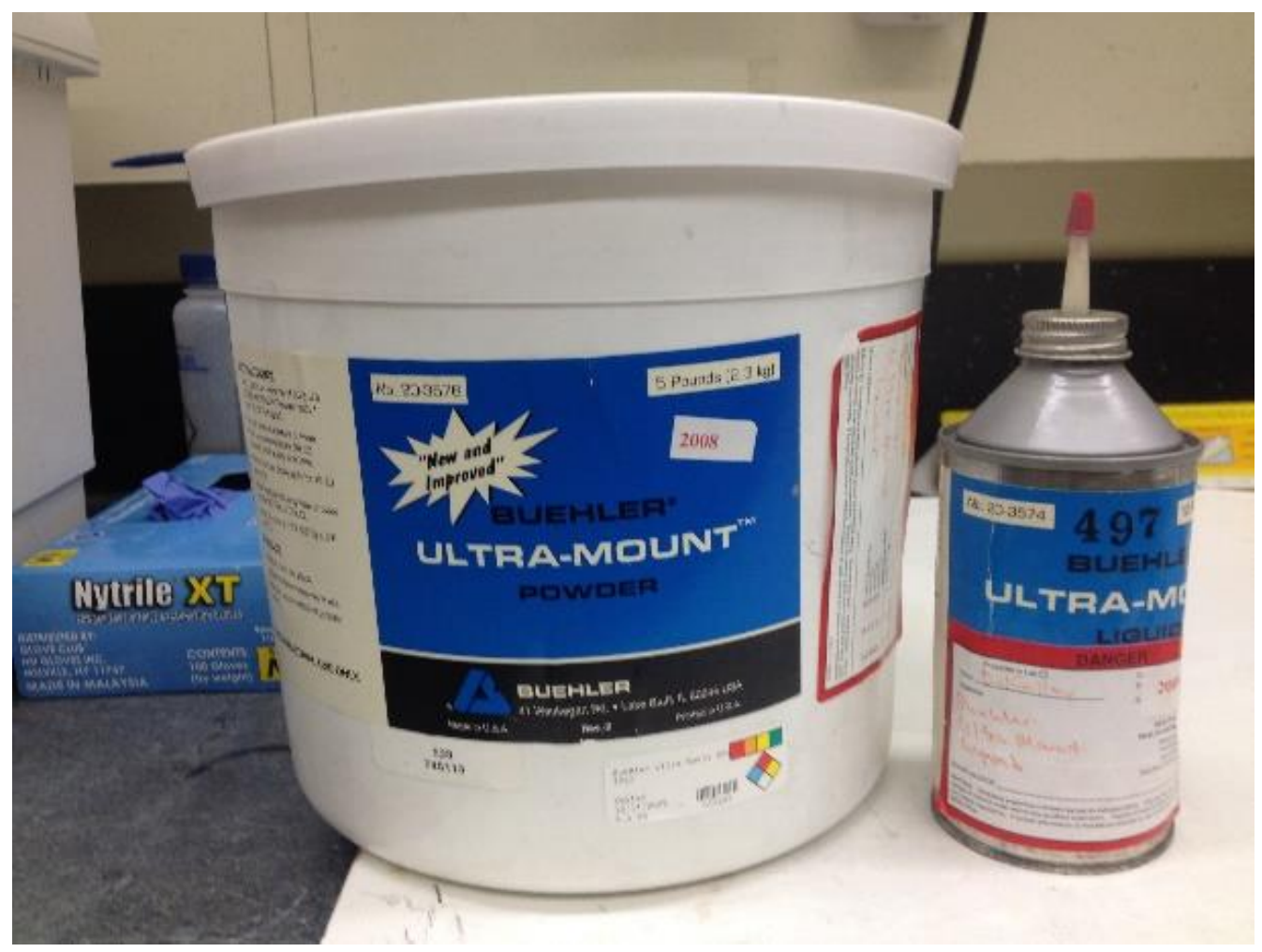

Figure 4. Non-radiopaque methyl methacrylate acrylic resin 

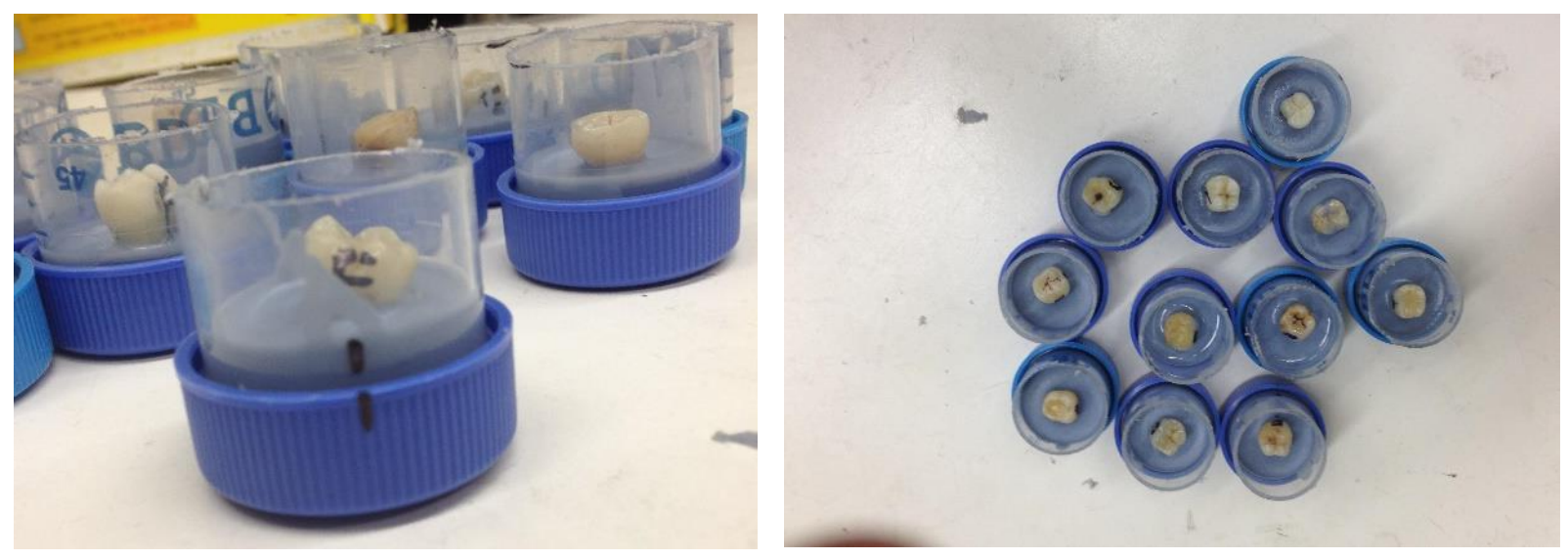

Figure 5. Tooth was mounted in the tube and buccal surface was marked

Scanning of the teeth were conducted at National Institute of Standards and Technology (NIST) (Gaithersburg, Maryland). A microCT-40 (Scanco Medical, Switzerland) with an isotropic voxel size $(18 \mu \mathrm{m})$ was utilized to scan the specimens. The radiographic settings were $75 \mathrm{kVp}$ and $114 \mu \mathrm{A}$ (Figure 6 ). All specimens were covered with wet paper towel and sealed with paraffin wax to keep the tooth moisturized during the experiment. 


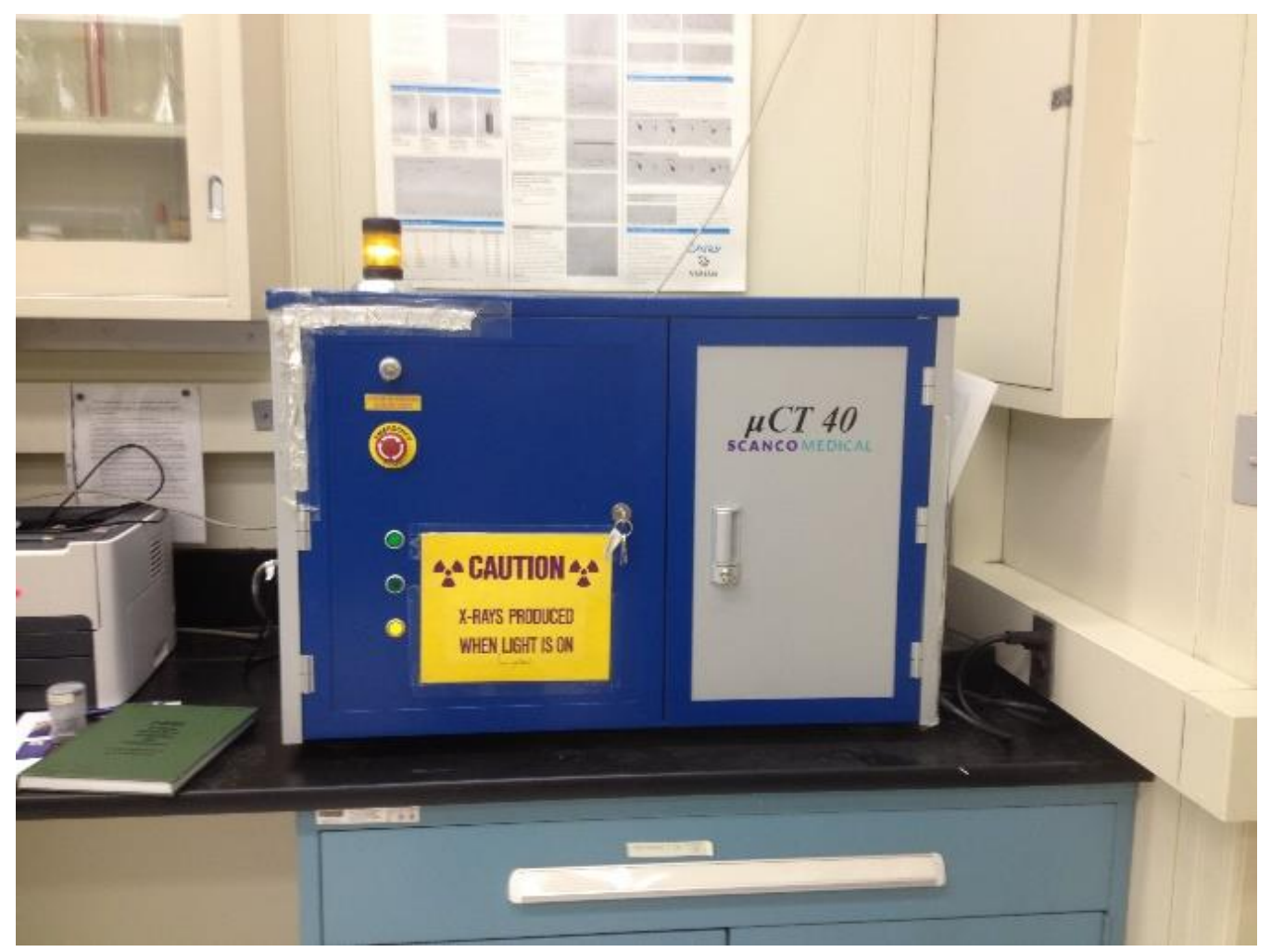

Figure 6. MicroCT-40 (Scanco Medical, Switzerland).

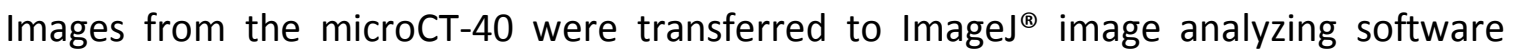
$(\mathrm{NIH}$, Bethesda, MD) to assess initial dentin thickness of the distal wall of each canal of each mesial root when measured $7 \mathrm{~mm}$ from the apex of each root. A cross sectional image at $7 \mathrm{~mm}$ was used for measurement. A straight line (Line 1) was drawn tangent to the outermost cementum layer of the distal wall from MB to ML canals. A second line (Line 2) was drawn parallel to Line 1 and tangent to the MB and ML distal surface of the canal space. Occasionally, a second parallel line to Line 1 (Line 3) would be drawn only if a point of tangency from both the $M B$ and $M L$ canal space could not be captured by Line 2, while maintaining parallelism to Line 1. A perpendicular line (Line 4) was drawn between Line 1 and Line 2, or 3 as needed, 
intersecting the MB canal space. A perpendicular line (Line 5) was drawn between Line 1 and Line 2, or 3 as needed, intersecting the ML canal space. Line 4 and 5 were used for preinstrumentation thickness measurement of the dentin thickness of the distal wall of the mesial root (Figure 7).

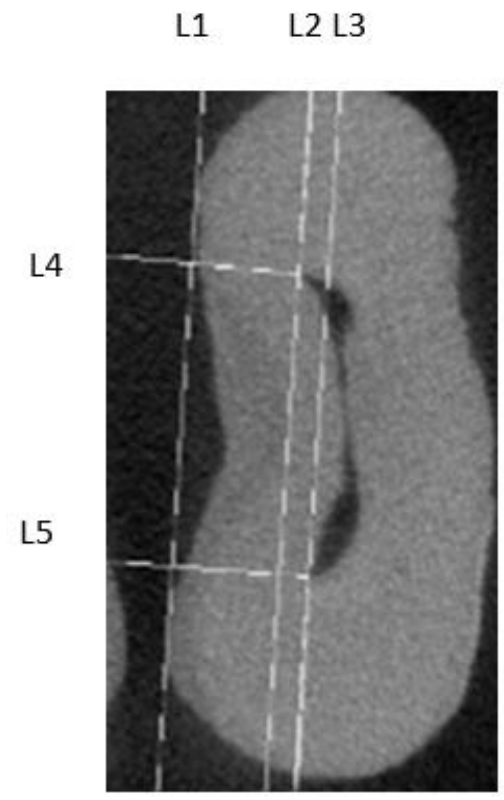

Figure 7. Method of measuring dentin thickness

One operator performed the mechanical shaping of the canals to minimize operator variation. The teeth initially were accessed with a 330 carbide bur (Brasseler USA, Savannah, GA, USA) in high speed handpiece with water coolant. Once in the chamber, Endo-Z bur (Dentsply, York, PA, USA) was used to enlarge the access outline and to facilitate locating the $\mathrm{MB}$ and ML orifices. Gates Glidden \#3 was then used at the orifice level to create straight line access as described by Isom. ${ }^{46}$ Canals were initially negotiated with a size $10 \mathrm{~K}$ file (Flexofile ${ }^{\circledR}$, Dentsply, York, PA, USA). The working length (WL) was established $1 \mathrm{~mm}$ short of the 
radiographic apex. A glide path was established with size $15 \mathrm{~K}$ file, (Flexofile ${ }^{\circledR}$, Dentsply, York, PA, USA) and canals were sequentially instrumented to length with NTR files (EndoSequence ${ }^{\circledR}$, Brasseler USA, Savannah, GA, USA) with varying apical sizes based upon group designation.

Torque $(2 \mathrm{~N}-\mathrm{cm})$ and speed $(500 \mathrm{rpm})$ were set on the rotary motor (Endo-MateDT, NSK Dental LLC, Hoffman Estates, IL, USA) according to the manufacturer's recommendations. The NTR files were used in a crown down fashion and followed the manufacturer's recommendations, utilizing an in and out motion. The canals were rinsed with $5 \mathrm{ml}$ of $2.5 \% \mathrm{NaOCl}$ between each file change using a 30 gauge side vented needle (Prorinse ${ }^{\circledR}$, Dentsply, York, PA, USA). The needle was inserted as deep as possible without binding in the canal. Once the canal was instrumented to length, a final rinse of sterile water was used and the canal was dried with paper points.

The teeth were scanned after canal preparation in a manner identical to the preinstrumentation scan. Each specimen's images were then transferred to Image ${ }^{\circledR}$ to measure RDT in a manner identical to the pre-instrumentation measurement. All specimens were covered with wet paper towel and sealed with paraffin wax to keep the tooth moisturized during the experiment (Figure 8 - 12). 
Group A (35)

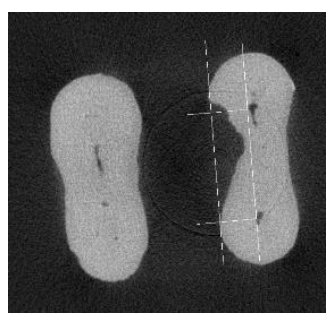

A1 before

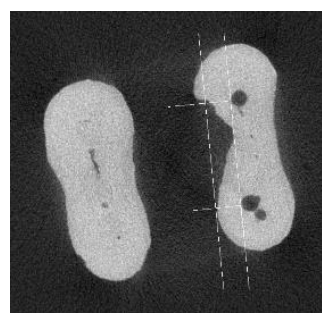

A1 after

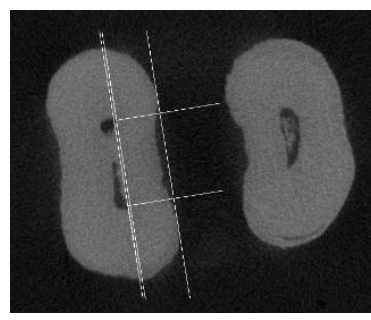

A2 before

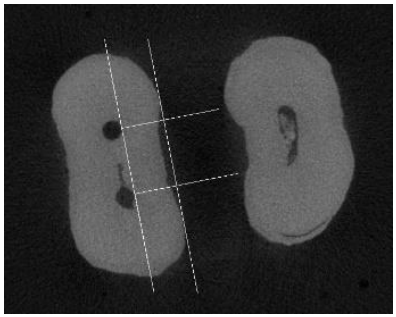

A2 after

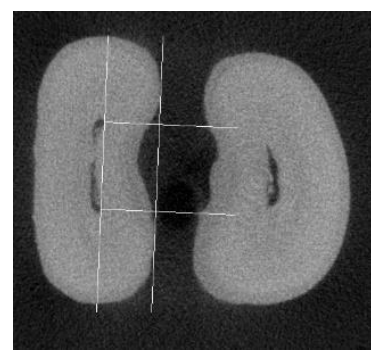

A3 before

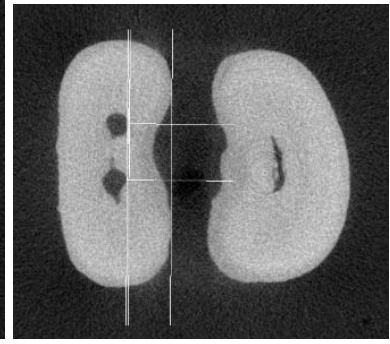

A3 after

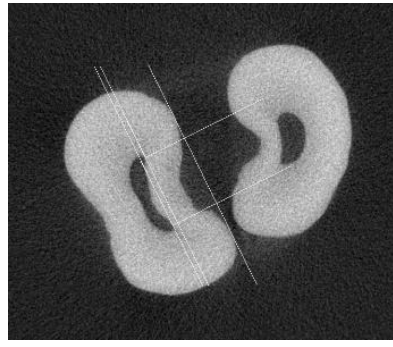

A4 before

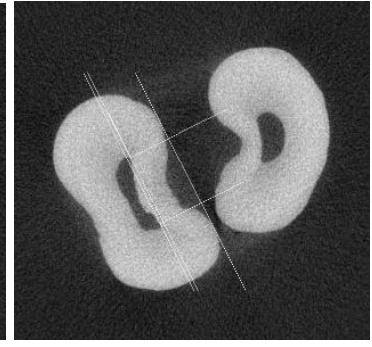

A4 after

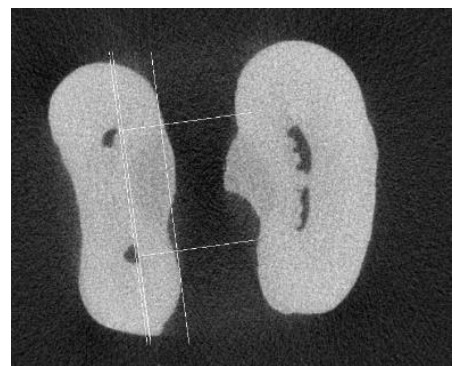

A5 before

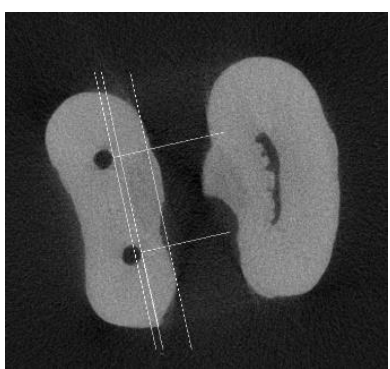

A5 after

Figure 8. Pre-op and post-op measurement images of Group A 
Group B (40)

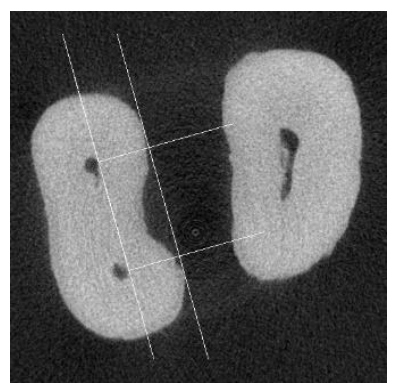

B1 before

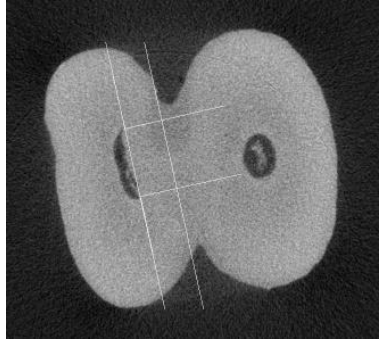

B3 before

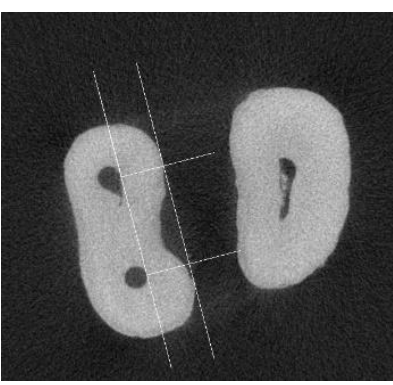

B1 after

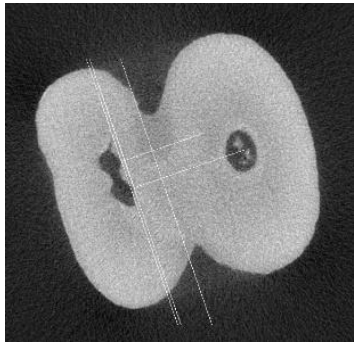

B3 after

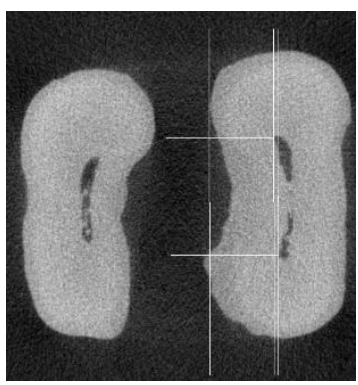

B2 before

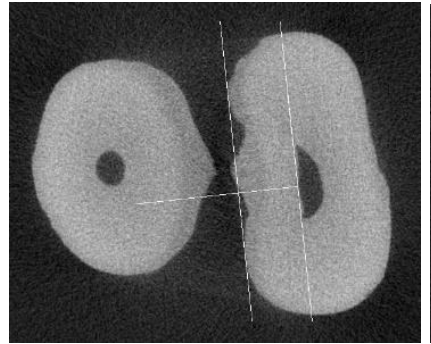

B4 before

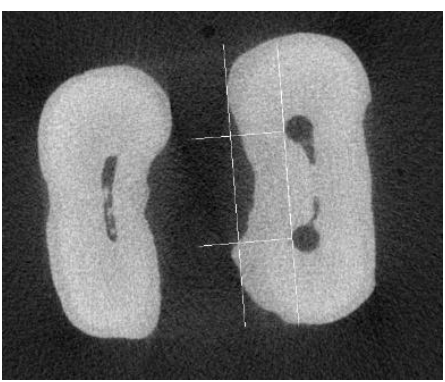

B2 after

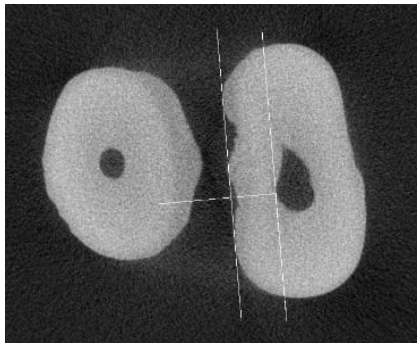

B4 after

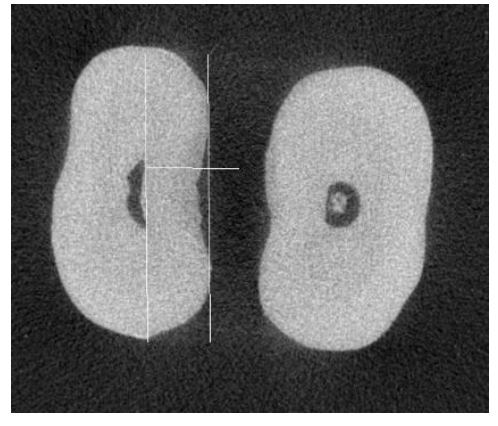

B5 before

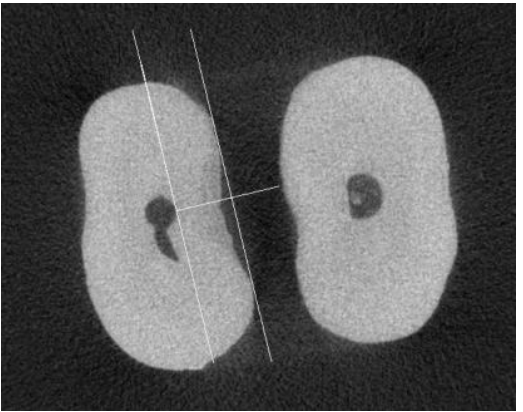

B5 after

Figure 9. Pre-op and post-op measurement images of Group B 
Group C (45)

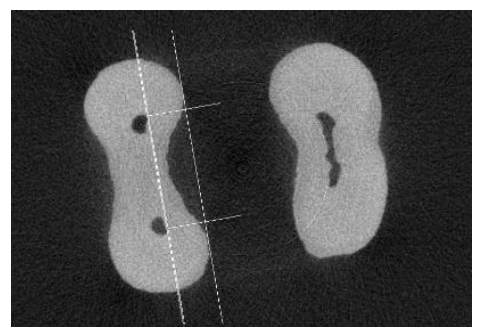

C1 before

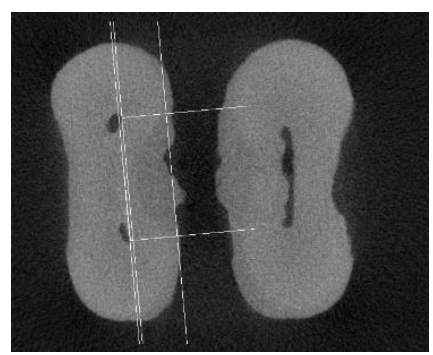

C3 before

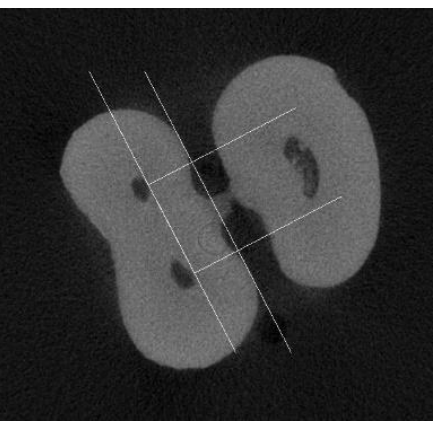

C5 before

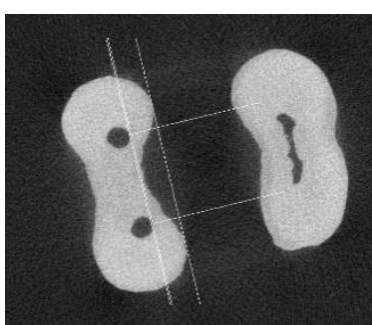

C1 after

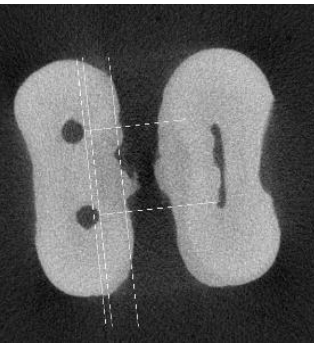

C3 after

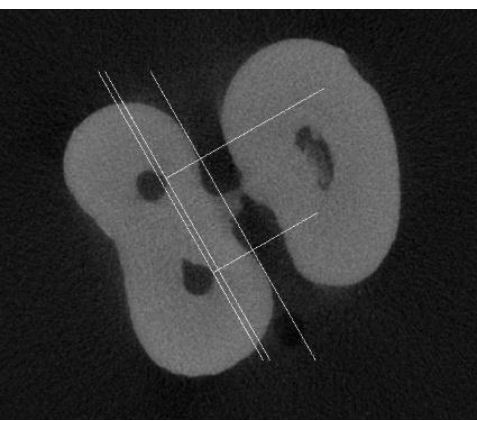

C5 after

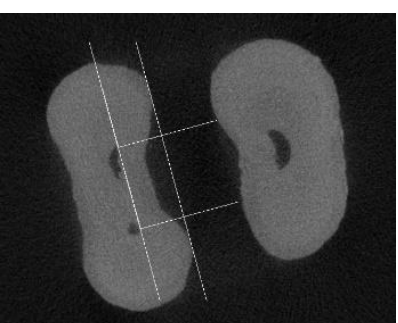

C2 before

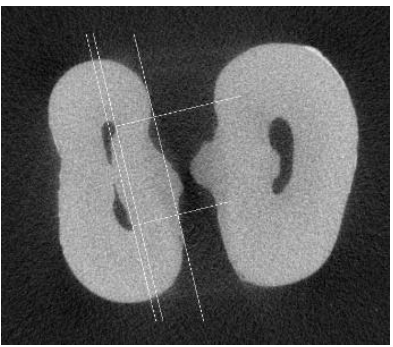

C4 before

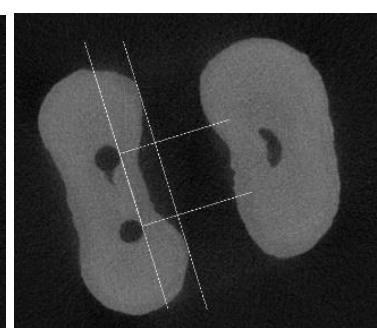

C2 after

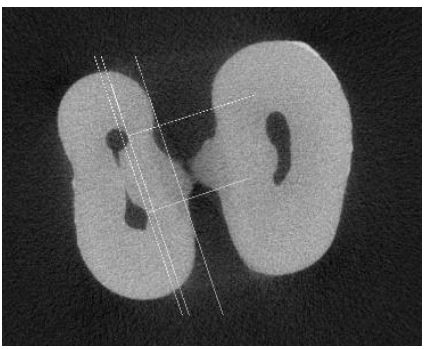

C4 after

Figure 10. Pre-op and post-op measurement images of Group C 


\section{Group D (50)}

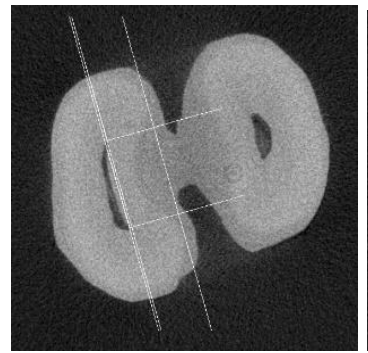

D1 before

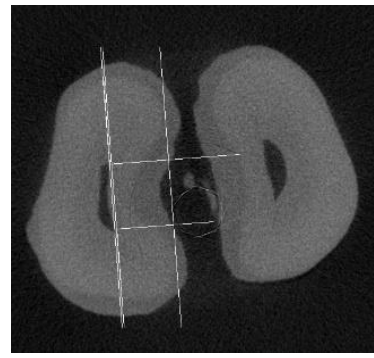

D3 before

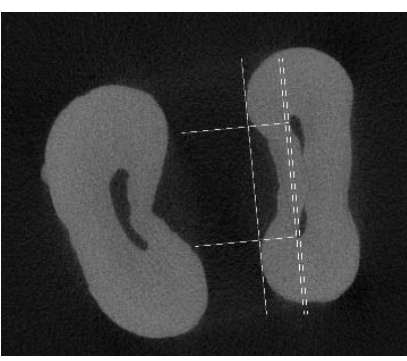

D5 before

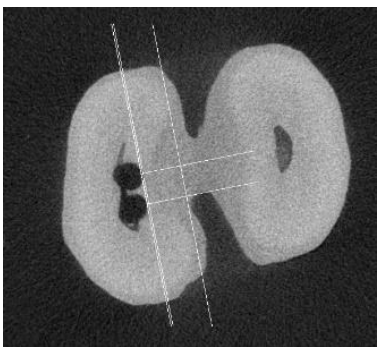

D1 after

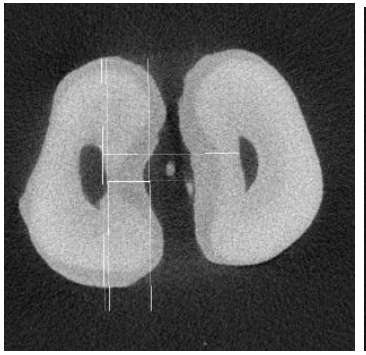

D3 after

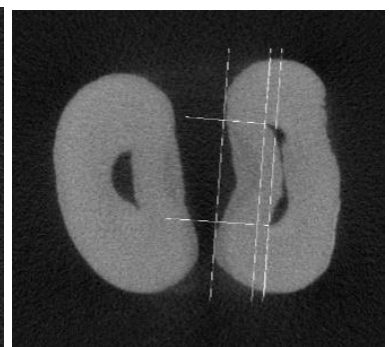

D2 before

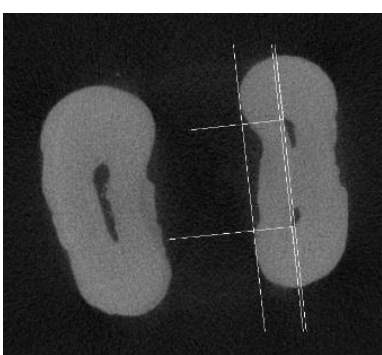

D4 before

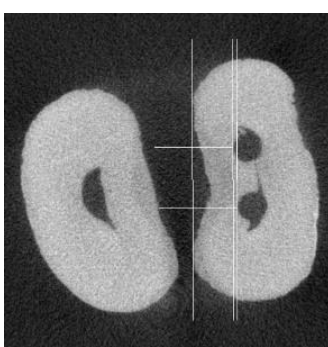

D2 after

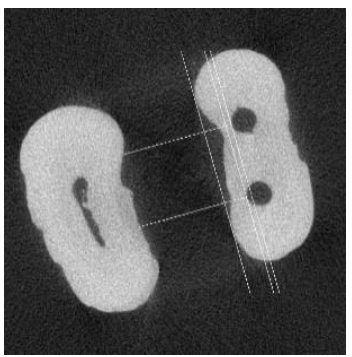

D4 after

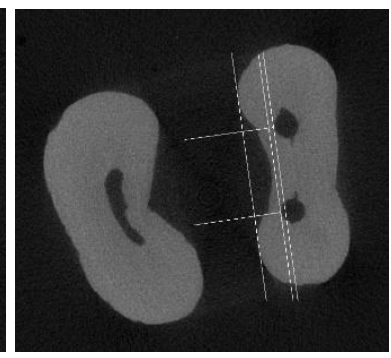

D5 after

Figure 11. Pre-op and post-op measurement images of Group D 


\section{Group E (55)}

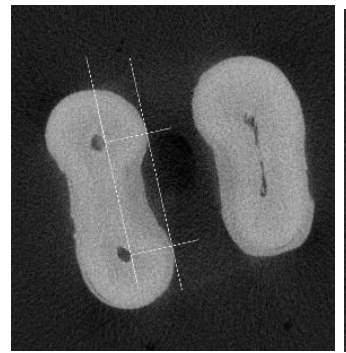

E1 before

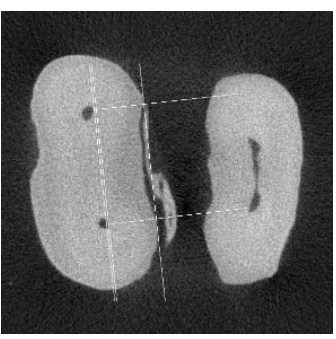

E3 before

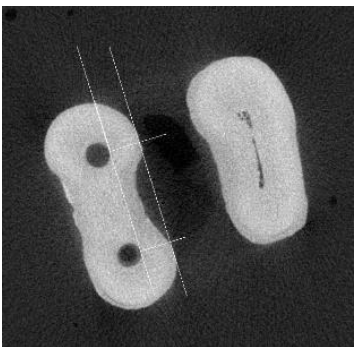

E1 after

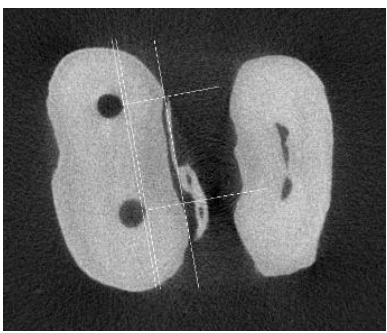

E3 after

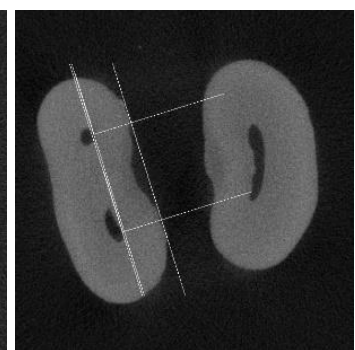

E2 before

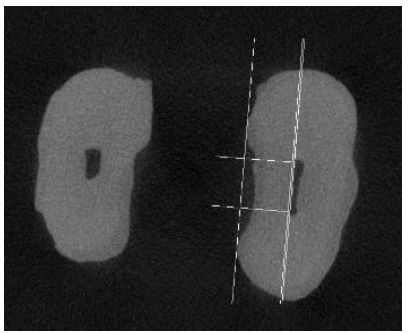

E4 before

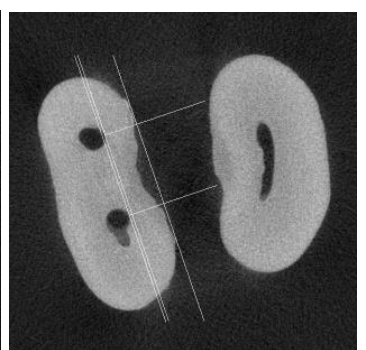

E2 after

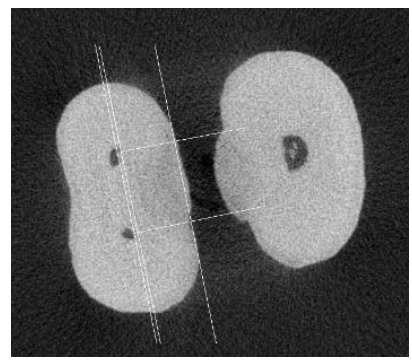

E5 before

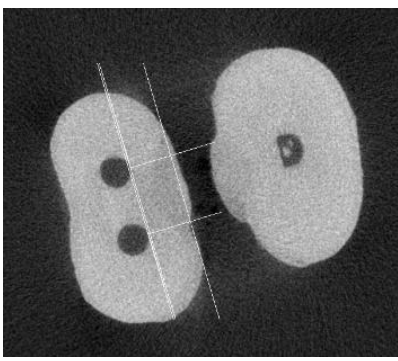

E5 after

Figure 12. Pre-op and post-op measurement images of Group $E$ 


\section{Statistical analysis}

The primary outcome variable of root dentin thickness, measured in millimeters, was analyzed. File size, the main predictor of root dentin thickness, was examined by group. Most teeth examined demonstrated multiple mesial canals. The correlation between the distal wall dentin thicknesses of both $\mathrm{MB}$ and $\mathrm{ML}$ of each tooth was assessed using Pearson correlation test. The mean value of distal wall dentin thickness was calculated in millimeters for each tooth, both for pre- and post-preparation distances. The Kruskal-Wallis test was used to analyze both how much dentin in millimeters was removed, and subsequently, the corresponding RDT between the various groups. All statistical analyses were performed in SAS 9.3 (SAS Institute, Inc., Cary, NC) and R 3.0.1. 


\section{Chapter IV}

\section{Results}

During instrumentation, all 25 specimens were found to be apically patent with size $10 \mathrm{~K}$ files, and patency was maintained during the instrumentation procedures. No separation of NTR instruments occurred during the mechanical preparation phase of the experiment. Based upon visual evaluation of radiographs, no visible transportation, perforation, ledge or apical stripping were detected. No post-instrumented roots demonstrated strip perforation in the distal wall at the $7 \mathrm{~mm}$ measurement level as seen on microCT images in any of the specimens evaluated.

Table 1 and Table 2 are pre- and post-mechanical preparation of the distal dentin wall thickness. Appendix (page 51) listed measurements of the preoperative mandibular mesial root curvature. 
Table 1. Dentin thickness (pre-preparation)

\begin{tabular}{|l|l|l|}
\hline & MB (mm) & ML (mm) \\
\hline A1 & 0.939 & 1.498 \\
\hline A2 & 1.371 & 1.447 \\
\hline A3 & 1.295 & 1.498 \\
\hline A4 & 1.524 & 1.346 \\
\hline A5 & 1.473 & 1.143 \\
\hline & & \\
\hline B1 & 1.422 & 1.346 \\
\hline B2 & 1.701 & 1.930 \\
\hline B3 & 0.990 & 0.685 \\
\hline B4 & 1.727 & N/A \\
\hline B5 & 1.473 & N/A \\
\hline & & \\
\hline C1 & 1.117 & 1.219 \\
\hline C2 & 1.117 & 1.219 \\
\hline C3 & 1.422 & 1.498 \\
\hline C4 & 1.270 & 1.727 \\
\hline C5 & 1.371 & 1.346 \\
\hline & & \\
\hline D1 & 0.838 & 0.838 \\
\hline D2 & 1.295 & 1.219 \\
\hline D3 & 0.965 & 1.092 \\
\hline D4 & 1.193 & 1.295 \\
\hline D5 & 1.295 & 1.244 \\
\hline & & \\
\hline E1 & 1.676 & 1.625 \\
\hline E2 & 1.422 & 1.498 \\
\hline E3 & 1.854 & 1.778 \\
\hline E4 & 1.422 & 1.295 \\
\hline E5 & 1.854 & 1.828 \\
\hline & & \\
\hline
\end{tabular}

$\mathrm{N} / \mathrm{A}=$ only one mesial canal present 
Table 2. Residual dentin thickness (post-preparation)

\begin{tabular}{|l|l|l|}
\hline & MB (mm) & ML $(\mathbf{m m})$ \\
\hline A1 & 0.762 & 1.0414 \\
\hline A2 & 1.295 & 1.270 \\
\hline A3 & 0.939 & 1.143 \\
\hline A4 & 1.498 & 1.016 \\
\hline A5 & 1.397 & 0.838 \\
\hline & & \\
\hline B1 & 1.371 & 1.270 \\
\hline B2 & 1.320 & 1.473 \\
\hline B3 & 0.660 & 0.355 \\
\hline B4 & 1.320 & N/A \\
\hline B5 & 1.117 & N/A \\
\hline & & \\
\hline C1 & 0.863 & 0.711 \\
\hline C2 & 0.736 & 0.838 \\
\hline C3 & 1.193 & 0.939 \\
\hline C4 & 0.965 & 1.574 \\
\hline C5 & 1.016 & 1.143 \\
\hline & & \\
\hline D1 & 0.254 & 0.33 \\
\hline D2 & 1.066 & 1.066 \\
\hline D3 & 0.838 & 0.355 \\
\hline D4 & 0.508 & 0.558 \\
\hline D5 & 0.635 & 0.660 \\
\hline & & 1.168 \\
\hline E1 & 1.244 & 1.117 \\
\hline E2 & 1.117 & 1.270 \\
\hline E3 & 1.447 & 0.787 \\
\hline E4 & 1.143 & 1.371 \\
\hline E5 & 1.498 & \\
\hline & & \\
\hline
\end{tabular}

$\mathrm{N} / \mathrm{A}=$ only one mesial canal present 
The correlation value between distal wall of preoperative dentin thickness of the MB and ML canals was 0.74 (value of -1 indicate specimen were completely opposite and 1 being the specimen were identical). Based on this result, it is seen that MB and ML canals have a great resemblance to each other and should be treated as a single entity (Figure 7).

\section{MB and ML Pre-op Dentin Thickness (mm)}

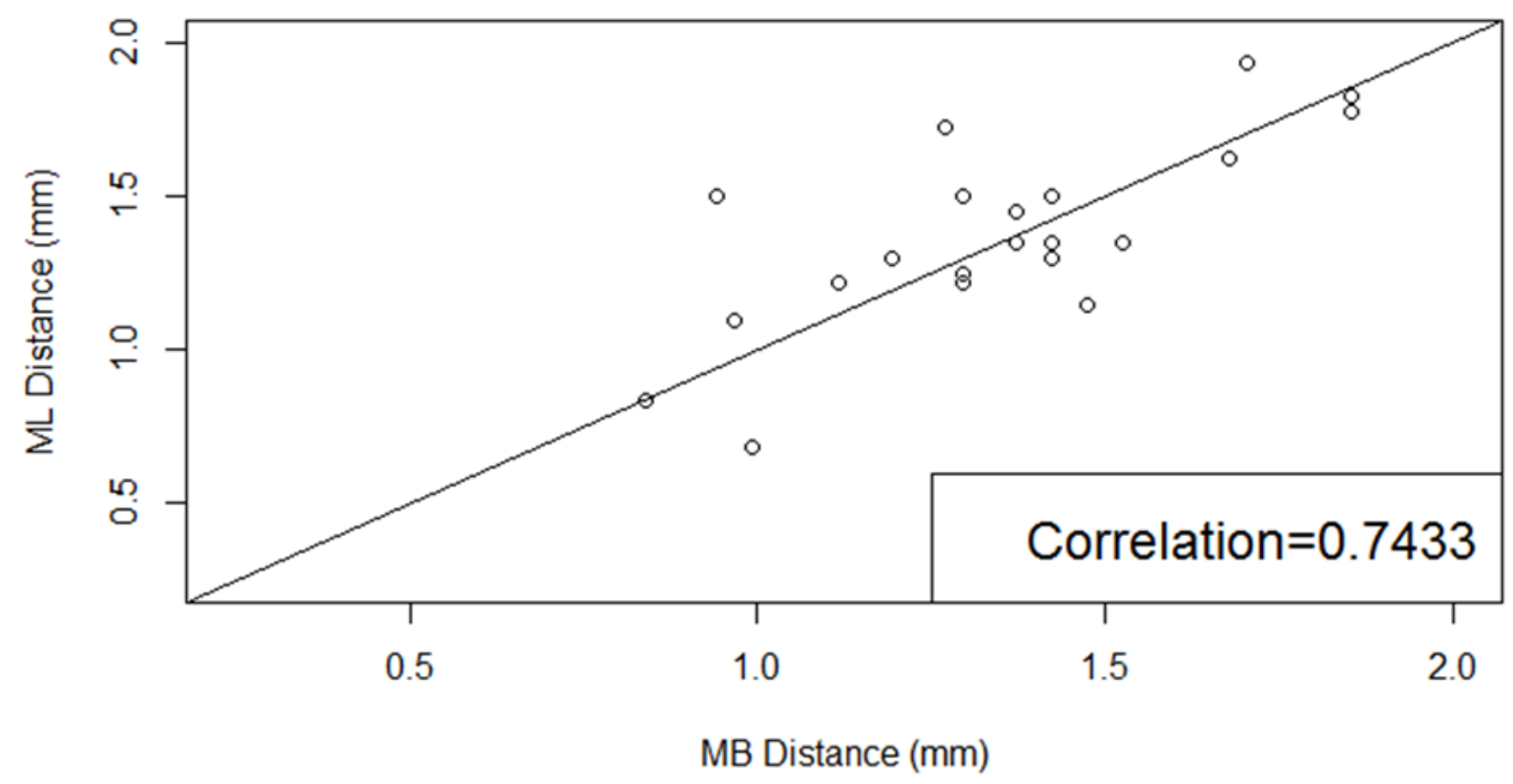

Figure 13. Pearson correlation for preoperatively distal wall dentin thickness of $\mathrm{MB}$ and $\mathrm{ML}$

The Kruskal-Wallis test was performed to evaluate whether there were differences between the 5 groups with respect to how much dentin was removed, and a statistically significant difference $(p=0.031)$ was found (figure 8$)$. The means and medians of the 5 groups are listed in the Table 3. The column chart is listed in the Figure 9. 


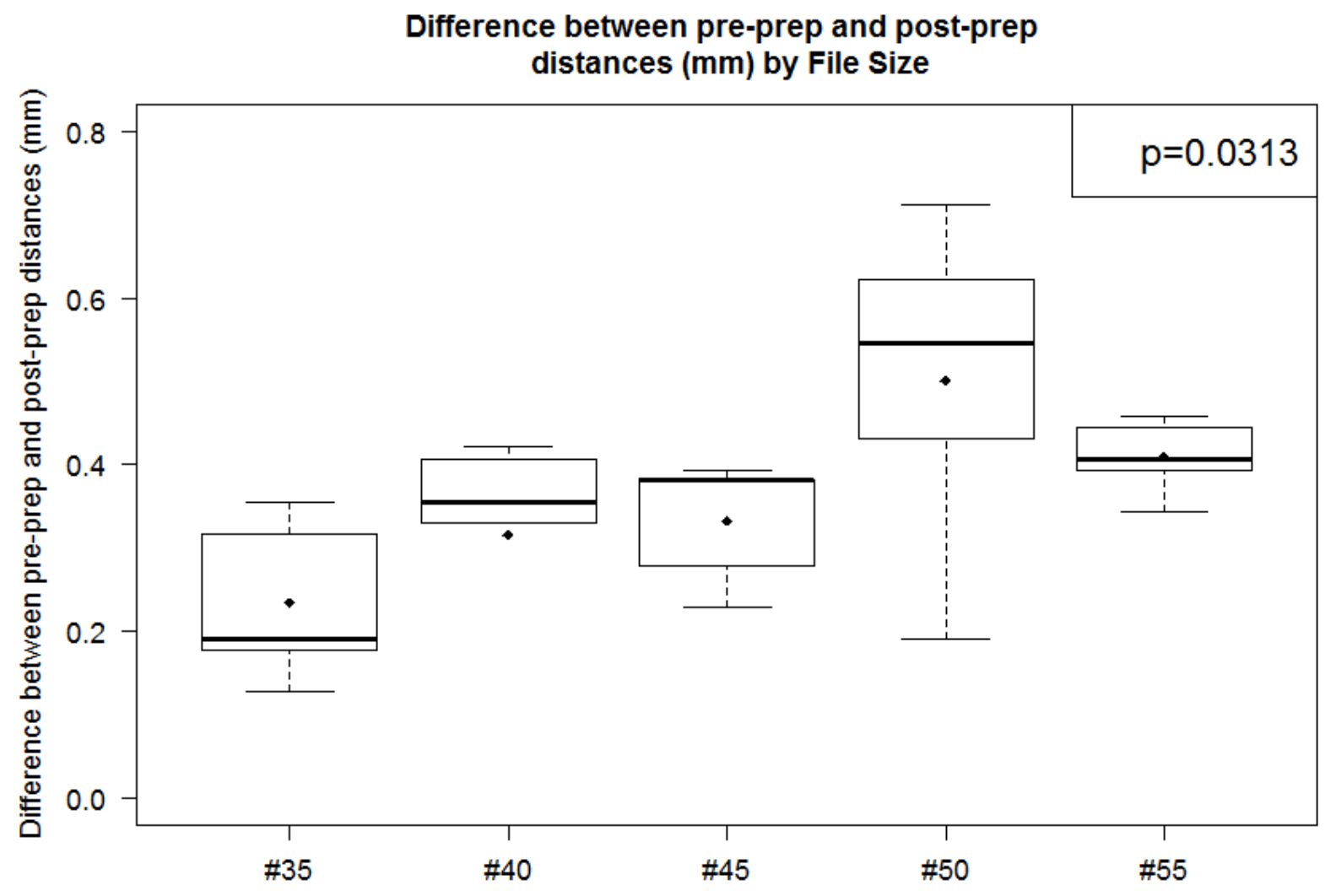

Note: top line is $75 \%$, middle line (Median) 50\%, bottom 25\%. The dot is the mean. The top line from the dotted line is measure of max and minimum.

Figure 14. Comparison of the dentin was removed by each file size group. 
Table 3. Mean $(\mathrm{mm})$ and Median $(\mathrm{mm})$ of the distal wall dentin was removed by NTR Instruments

\begin{tabular}{|l|l|l|l|l|l|}
\hline Group & Mean (mm) & SD & Median (mm) & $\begin{array}{l}\text { Lower } \\
\text { Quartile } \\
(25 \%)\end{array}$ & $\begin{array}{l}\text { Upper } \\
\text { Quartile } \\
(75 \%)\end{array}$ \\
\hline A (35) & 0.233 & 0.097 & 0.190 & 0.178 & 0.317 \\
\hline B (40) & 0.315 & 0.145 & 0.355 & 0.330 & 0.406 \\
\hline C (45) & 0.332 & 0.742 & 0.381 & 0.279 & 0.381 \\
\hline D (50) & 0.500 & 0.201 & 0.546 & 0.431 & 0.622 \\
\hline E (55) & 0.408 & 0.045 & 0.406 & 0.393 & 0.444 \\
\hline
\end{tabular}

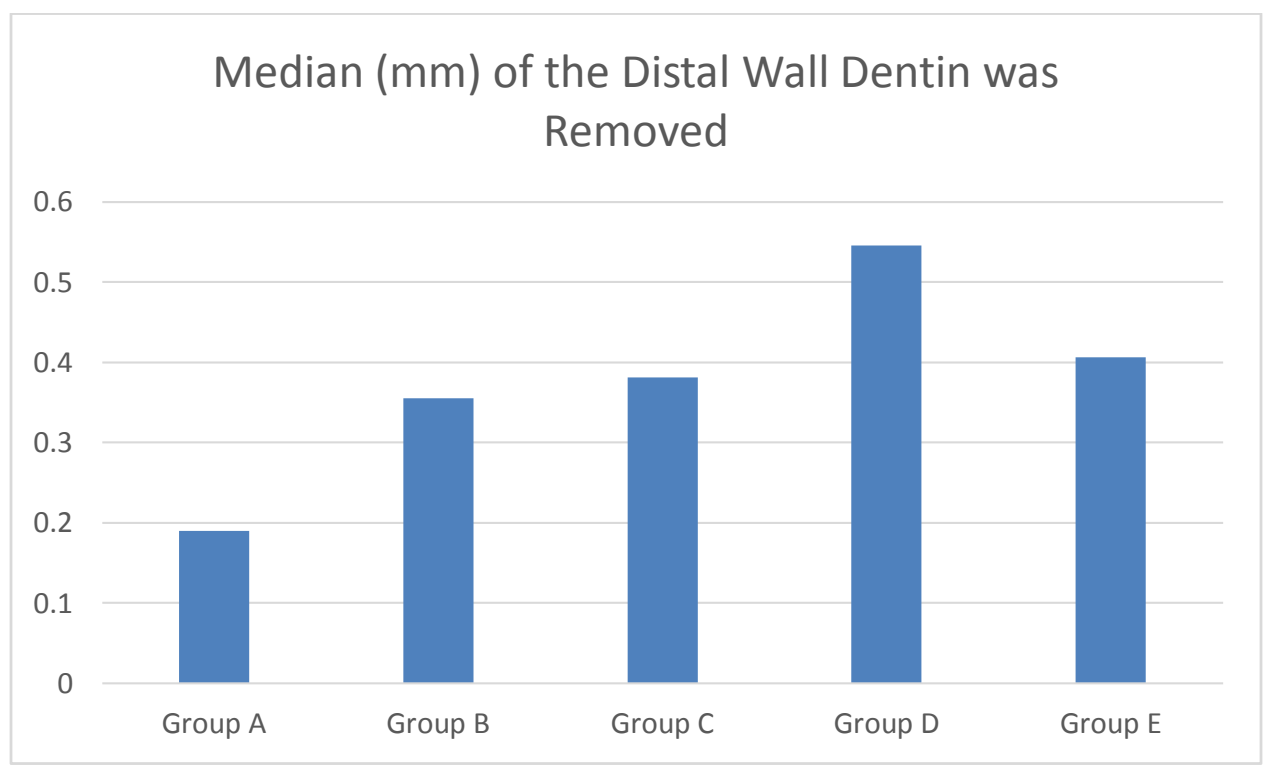

Figure 15. Median ( $\mathrm{mm}$ ) of the dentin was removed by Groups 
A statistically significant difference was found between the sizes of the NTR files among the 5 groups when comparing the distal wall residual dental thickness $(P=0.001)$ (Figure 10). The means and medians of the RDT among the five groups are listed in Table 4 . The column chart is listed in Figure 11.

\section{Residual Dentin Thickness ( $\mathrm{mm}$ ) by File Size}

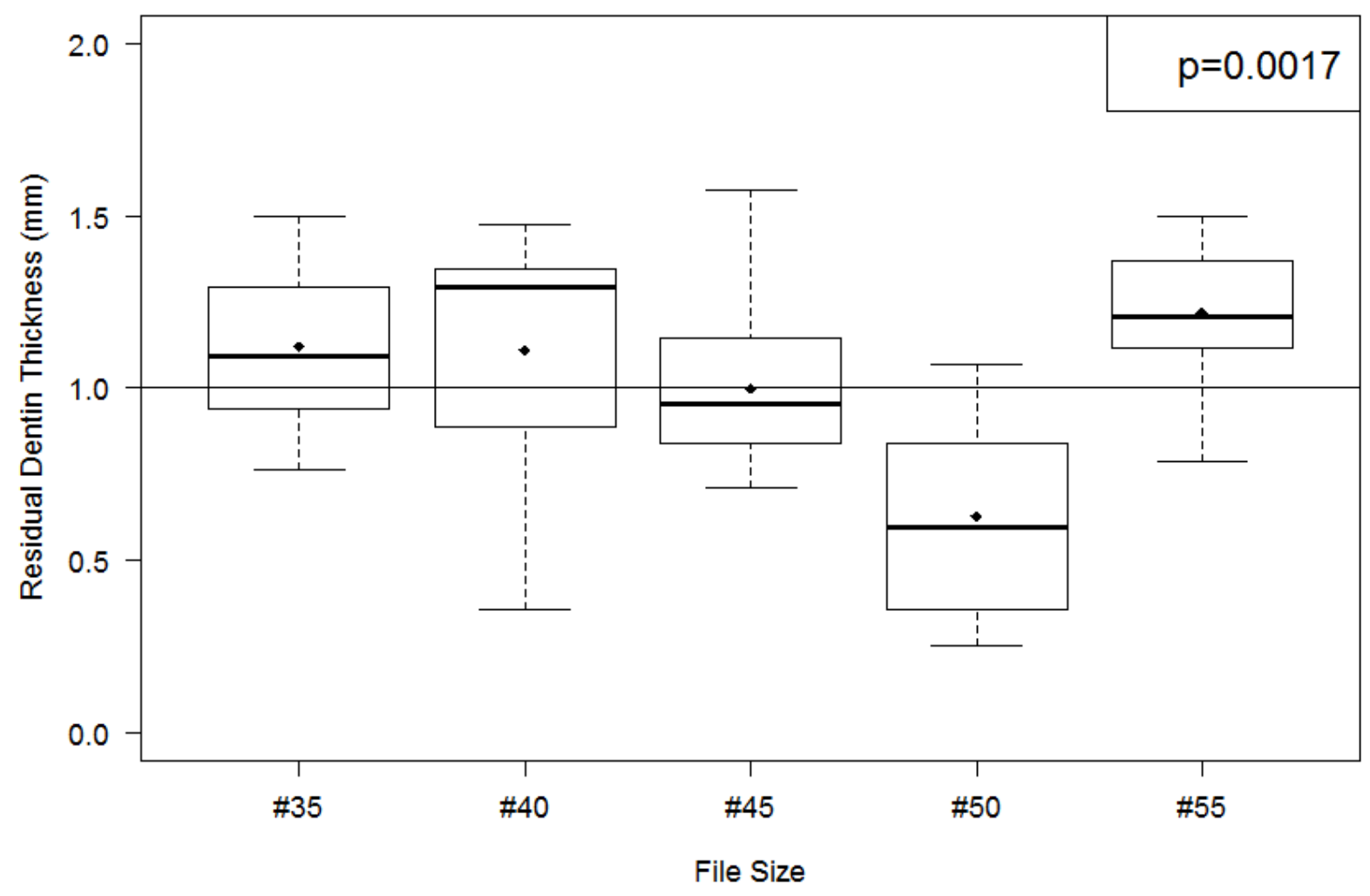

Figure 16. Residual dentin thickness by file size 
Table 4. Mean $(\mathrm{mm})$ and Median $(\mathrm{mm})$ of RDT by file size

\begin{tabular}{|l|l|l|l|l|l|}
\hline Group & Mean $(\mathrm{mm})$ & SD & Median $(\mathrm{mm})$ & $\begin{array}{l}\text { Lower } \\
\text { Quartile } \\
(25 \%)\end{array}$ & $\begin{array}{l}\text { Upper } \\
\text { Quartile } \\
(75 \%)\end{array}$ \\
\hline A (35) & 1.120 & 0.242 & 1.092 & 0.939 & 1.295 \\
\hline B (40) & 1.111 & 0.393 & 1.295 & 0.889 & 1.346 \\
\hline C (45) & 0.998 & 0.256 & 0.952 & 0.838 & 1.143 \\
\hline D (50) & 0.627 & 0.289 & 0.596 & 0.355 & 0.838 \\
\hline E (55) & 1.216 & 0.203 & 1.206 & 1.117 & 1.371 \\
\hline
\end{tabular}

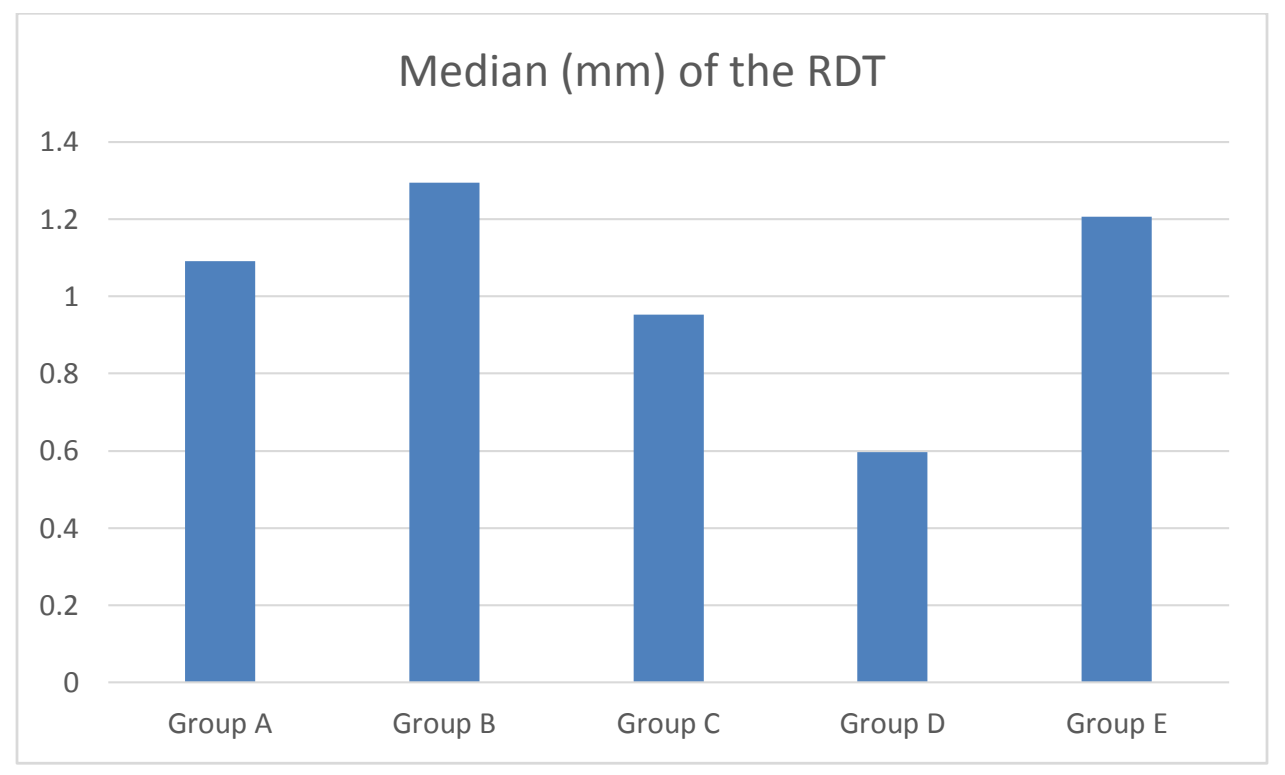

Figure 17. Median (mm) of RDT by Groups 


\section{Discussion}

The aim of this study was to assess the residual dentin thickness of the distal wall of mandibular mesial roots after canals were enlarged with $4 \%$ constant tapered NTR files with medium to large size tips. A statistically significant difference in RDT among the five groups after mechanical instrumentation was identified. Most RDT stayed within the $1 \mathrm{~mm}$ range except Group D (50.04); therefore, the null hypothesis is rejected.

Mesial roots of mandibular molars were chosen for the study due to their inherently oval and conical shapes. ${ }^{47}$ This uniquely shaped canal creates distinct challenges to mechanically cleaning and shaping the root canal space. According to Muller, ${ }^{55}$ the average primary curvature is between $20^{\circ}$ to $30^{\circ}$. This study found that there was a $100 \%$ chance of curvature in all molars, with molars instrumented exhibiting a degree of curvature within the previously mentioned $20^{\circ}$ to $30^{\circ}$ range. Lesberg et al ${ }^{48}$ showed that canal transportation usually occurs at the curvature level of the distal surface of the canal. The author further stated that the greater the curvature, the more likely the operator is to create canal transportation toward the distal concavity of the root. A previous study by Junior et al., showed that the MB and ML canals are often similar to each other in curvature and dentin volume ${ }^{44}$. The current study's analysis between the MB and ML distal surface dentin thickness is similar (correlation = 0.743) which is in accordance with Junior's study; therefore, both canals (MB and $M L$ ) were treated as one subject. The mean of MB and ML canals was calculated and utilized during statistical analysis. 
Using Gates-Glidden \#3 to flare the coronal section is an important step to create so called straight line access. It is recommended to use Gates-Glidden drills in an anti-curvature motion at the orifice level to remove the cervical bulge, but stopping prior to the level of the furcation to prevent any unnecessary dentin removal. ${ }^{46}$

The danger zone can vary in locale among teeth and it can be difficult to determine the exact location of the thinnest and most curved areas in mandibular mesial roots. Studies have considered $1.5 \mathrm{~mm}$ to $2 \mathrm{~mm}$ below the furcation as a landmark to aid in determining the danger zone location. ${ }^{22,49}$ Other studies have used between $6 \mathrm{~mm}$ to $8 \mathrm{~mm}$ coronal from the apex as a landmark to map the danger zone region. ${ }^{23,56}$

The current study selected $7 \mathrm{~mm}$ coronal from the apex, as described in Zuckerman's ${ }^{38}$ and Ouzounian's study. ${ }^{56}$ The enlargement of the apex from a size 35.04 to the largest size 55.04 in this study was based on Brunson's ${ }^{14}$ and Falk's study. ${ }^{15}$ It is recommended to enlarge the canal space to a minimum size of 35 to 40 to maintain a balance between the volume of irrigant introduced into the canal and the integrity of the root structure. ${ }^{13,14}$ According to Falk's study, ${ }^{15}$ anything larger than an apical size of 60 did not improve irrigation efficacy. However, in the current study, it is the author's opinion that a size 60.04 preparation of the mesial mandibular roots would compromise the integrity of the root structure; therefore, the current study used a size 55.04 as the largest apical enlargement.

There are many brands of NTR instruments to select from; however, only a few brands of NTR instruments carry sizes larger than size 50 . EndoSequence ${ }^{\circledR}$ is one of the few brands of NRT instruments to carry such a size or larger. Their NTR files are a triangular design with no 
radial land which enhances the flexibility of the file and increases cutting efficiency. Its lower helical angle with alternating contact points acts similar to a reamer which reduces the NTR files tendency to 'suck into' the canal. ${ }^{50-52}$

Pearson correlation test was used to determine if a correlation existed between the MB and ML canals of distal wall dentin thickness. This is an important step in deciding whether or not the MB and ML can be treated as separate entities during the statistical analysis. The results revealed that the preoperative distal wall distance of the MB and ML were highly correlated (Pearson correlation $=0.743)$; therefore, the mean of the two canals of each specimen was utilized for further analysis. Because of this determination, the sample size was reduced by half since the $\mathrm{MB}$ and $\mathrm{ML}$ cannot be considered independent observations. Due to the small sample sizes of this study, the Kruskal-Wallis test, a non-parametric test, was used to analyze the data instead of ANOVA (which is normally reserved for larger sample sizes with the assumption of normally distributed results). The Kruskal-Wallis test utilizes the median of the data (instead of the mean) to determine whether or not there is at least one group that is different from the rest. No further comparison test between each group was employed, also due to the small sample size, which has limited power to detect the true differences among each test group.

The amount of distal wall dentin that was mechanically removed ranged from low of $0.190 \mathrm{~mm}$ (Group A) to the high of $0.546 \mathrm{~mm}$ (Group D). The Kruskal-Wallis test was able to detect a statistical difference among the five groups $(P=0.031)$. A linear relationship exists between the file size used for canal preparation and the volume of dentin that was removed. As the size of the file used for canal preparation increased, the amount of dentin volume 
removed increased, as shown in Figure 9. These findings are in agreement with Junior's study. Junior ${ }^{44}$ found that the larger tip size removed more distal wall dentin than the smaller file size and dentin volume removal was more significant in the mid-root section than the apical-root section of the mandibular mesial root. Junior also concluded that the distal wall dentin of the mid-root region was removed more than the mesial wall of the mid-root in the canal space. ${ }^{44}$

Postoperatively, a significant difference was found with respect to the RDT among the five groups based on the Kruskal-Wallis test $(P=0.001)$. This is in disagreement with Zuckerman's study. Zuckerman ${ }^{38}$ concluded that with an apical preparation to a size \#50, there are no statistically different RDT changes between pre- and post-preparation. Both Zuckerman's and Junior's studies confirmed the overall safety of using NTR files to prepare the apex to larger sizes. ${ }^{38,44}$ Based on the current study, Group A (1.092 mm), Group B (1.295 $\mathrm{mm})$, Group C (0.952 mm), and Group E $(1.206 \mathrm{~mm})$ had similar median RDT values which agree with Zuckerman's and Junior's investigations. However, Group D $(0.596 \mathrm{~mm})$ had a significantly less median RDT value than any other groups, which created the significant difference.

The mean value of pre-instrumented distal wall dentin thickness at $7 \mathrm{~mm}$ for the $\mathrm{MB}$ canal was $1.361 \mathrm{~mm}(\mathrm{SD}=0.275)$ and $1.381 \mathrm{~mm}(\mathrm{SD}=0.296)$ for the $\mathrm{ML}$ canal. This was similar to the value of $1.21 \mathrm{~mm}(S D=0.21)$ that was reported by Zuckerman. ${ }^{38}$ The mean RDT value of the distal wall reported by Zuckerman ${ }^{38}$ was $0.92 \mathrm{~mm}(\mathrm{SD}=0.19)$. Ouzounian ${ }^{56}$ found the mean RDT at $7 \mathrm{~mm}$ to be approximately $0.6 \mathrm{~mm}$. The RDT of the current study among the five groups ranged from the thinnest of $0.627 \mathrm{~mm}(S D=0.274)$ (Group $D 50.04)$ to the thickest of $1.217(S D=0.193)$ which is similar to Ouzounian and Zuckerman's studies. 
Ouzounian ${ }^{56}$ recommended preserving $1 \mathrm{~mm}$ of dentin thickness to maintain the integrity of the root structure in the mid-root section. In this study, the mean value of RDT was close to $1 \mathrm{~mm}$ among all groups, except Group D (50.04) with a significantly lower mean value of $0.627 \mathrm{~mm}$. The mean RDT of this study was similar to the Zuckerman's ${ }^{38}$ study at the $7 \mathrm{~mm}$ section when the canals were instrumented to size 50 with LightSpeed ${ }^{\circledast}$. It is also comparable to Junior's ${ }^{44}$ study where the mean RDT was $0.8 \mathrm{~mm}$ at the $5 \mathrm{~mm}$ level after the canals were enlarged to size 40.04 .

Canal preparation should not exceed $1 / 3$ of the width of the root width as suggested by other studies ${ }^{39-41}$ to preserve the integrity of root structure. As this study compares the preinstrumentation and post-instrumentation value of dentin thickness of the distal surface of the mesial root, it is best to compare investigations that use specific values of RDT, such as $1 \mathrm{~mm}$, described by several studies ${ }^{42,43,56}$ as opposed to arbitrary rules, such as the $1 / 3$ rule.

Due to the complex anatomy of mesial roots of mandibular molars, even with the larger size NTR instruments, many isthmuses and fins in these roots in this study were left untouched. This is in agreement with Peters et al ${ }^{19}$ that $35 \%$ of the root canal space is left untouched. Based on this observation, the importance of using antibacterial irrigants such as $\mathrm{NaOCl}$ and $\mathrm{CHX}$, along with devices such as passive ultrasonic irrigation systems to further disinfect the canal space, cannot be overemphasized.

In the current study, the unexpected results were observed in Group D for the RDT, which the author considers as an "outlier". The finding of this outlier may be due to the small sample size and non-standardization of canal lengths, degree of curvatures, and preoperative 
dentin thickness. In this study, the root lengths were intentionally not standardized in order to more closely simulate clinical conditions. For any future investigations, the author would recommend scanning and measuring the preoperative samples so that specimens can be categorized together with their similarities of root length, degree of canal curvature, and preoperative dentin thickness. The specimens would then be selected from those with similar parameters to form each individual group for the study. With this method, the data would be more accurately and evenly distributed. Even though some of the RDT data appeared to be different within one of the groups, the clinical implication of this study is still significant. Based on observations made from this study, clinicians should proceed with caution during the mechanical preparation in mandibular mesial roots, since a conventional periapical radiograph does not provide the diagnostic means to determine the precise width of dentin thickness. It should not be falsely assumed that a smaller size mechanical preparation would be safer than a larger size in preventing iatrogenic occurrences.

The use of microCT provided a non-destructive way to precisely measure the thickness of the roots investigated. Similar studies have sectioned the roots using disks to pre-measure the thickness of the root and then re-assemble the root to allow for cleaning and shaping. Such a method could lead to inaccuracy by both removing un-necessary dentin and the difficulty in precise alignment of the disk. Correlation between a preoperative periapical radiograph and preoperative dentin thickness would be an interesting area of investigation for a future study. The technology of microCT has opened up many possibilities for future similar studies. 


\section{Chapter V}

\section{Conclusion}

It was concluded that the original root anatomy and the pre-preparation dentin width are the biggest factors that determine the amount of dentin removed by files in the mid-root of the canal. This is best illustrated by the results of the Group D (50.04) as it compares to Group

E (55.04). Group E (55.04) had greater value of RDT than Group D (50.04). Logically, one would assume that a larger file would remove more dentin and have a lower value of RDT postoperatively. However, the results of this study were the opposite of what would have been anticipated. The author disagrees with statements made by Garala et al. ${ }^{53}$ and Junior et al. ${ }^{44}$ indicating that the size of the file (up to 55.04) plays an insignificant role in the amount of dentin removal concerning overall safety of the usage of medium to large $4 \%$ tapered NTR instruments during the preparation of mandibular mesial root canals. It is speculation that such statements can only be made when the dentin thickness is determined preoperatively. Cone beam computed tomography has been introduced in recent years. With its ability to capture tooth anatomy in a three dimensional image, a clinician may one day be able to determine a precise size to mechanically prepare the root canal beforehand without potentially compromising the tooth's structural integrity. 


\section{Work Cited}

1. KAKEHASHI S, STANLEY HR, FITZGERALD RJ. The effects of surgical exposures of dental pulps in germ-free and conventional laboratory rats. Oral Surg Oral Med Oral Pathol. 1965;20:340349.

2. Sjogren U, Figdor D, Persson S, Sundqvist G. Influence of infection at the time of root filling on the outcome of endodontic treatment of teeth with apical periodontitis. Int Endod J. 1997;30(5):297-306.

3. Schilder H. Cleaning and shaping the root canal. Dent Clin North Am. 1974;18(2):269-296.

4. Bystrom A, Sundqvist G. Bacteriologic evaluation of the efficacy of mechanical root canal instrumentation in endodontic therapy. Scand J Dent Res. 1981;89(4):321-328.

5. Tan BT, Messer $\mathrm{HH}$. The quality of apical canal preparation using hand and rotary instruments with specific criteria for enlargement based on initial apical file size. J Endod. 2002;28(9):658664.

6. Siqueira JF,Jr, Lima KC, Magalhaes FA, Lopes HP, de Uzeda M. Mechanical reduction of the bacterial population in the root canal by three instrumentation techniques. $J$ Endod.

1999;25(5):332-335.

7. Rollison S, Barnett F, Stevens RH. Efficacy of bacterial removal from instrumented root canals in vitro related to instrumentation technique and size. Oral Surg Oral Med Oral Pathol Oral Radiol Endod. 2002;94(3):366-371.

8. Orstavik D, Kerekes K, Molven O. Effects of extensive apical reaming and calcium hydroxide dressing on bacterial infection during treatment of apical periodontitis: A pilot study. Int Endod J. 1991;24(1):1-7.

9. Wu MK, Wesselink PR. Efficacy of three techniques in cleaning the apical portion of curved root canals. Oral Surg Oral Med Oral Pathol Oral Radiol Endod. 1995;79(4):492-496.

10. Dalton BC, Orstavik D, Phillips C, Pettiette M, Trope M. Bacterial reduction with nickeltitanium rotary instrumentation. J Endod. 1998;24(11):763-767.

11. Usman N, Baumgartner JC, Marshall JG. Influence of instrument size on root canal debridement. J Endod. 2004;30(2):110-112.

12. Card SJ, Sigurdsson A, Orstavik D, Trope M. The effectiveness of increased apical enlargement in reducing intracanal bacteria. J Endod. 2002;28(11):779-783. 
13. Ram Z. Effectiveness of root canal irrigation. Oral Surg Oral Med Oral Pathol. 1977;44(2):306-312.

14. Brunson M, Heilborn C, Johnson DJ, Cohenca N. Effect of apical preparation size and preparation taper on irrigant volume delivered by using negative pressure irrigation system. $J$ Endod. 2010;36(4):721-724.

15. Falk KW, Sedgley CM. The influence of preparation size on the mechanical efficacy of root canal irrigation in vitro. J Endod. 2005;31(10):742-745.

16. Weine FS, Kelly RF, Lio PJ. The effect of preparation procedures on original canal shape and on apical foramen shape. J Endod. 1975;1(8):255-262.

17. Abou-Rass M, Frank AL, Glick DH. The anticurvature filing method to prepare the curved root canal. J Am Dent Assoc. 1980;101(5):792-794.

18. Bower RC. Furcation morphology relative to periodontal treatment. furcation entrance architecture. J Periodontol. 1979;50(1):23-27.

19. Peters OA. Current challenges and concepts in the preparation of root canal systems: $A$ review. J Endod. 2004;30(8):559-567.

20. Schafer E, Erler M, Dammaschke T. Comparative study on the shaping ability and cleaning efficiency of rotary mtwo instruments. part 2. cleaning effectiveness and shaping ability in severely curved root canals of extracted teeth. Int Endod J. 2006;39(3):203-212.

21. Sonntag D, Ott M, Kook K, Stachniss V. Root canal preparation with the NiTi systems K3, mtwo and ProTaper. Aust Endod J. 2007;33(2):73-81.

22. Berutti E, Fedon $G$. Thickness of cementum/dentin in mesial roots of mandibular first molars. J Endod. 1992;18(11):545-548.

23. Lim SS, Stock CJ. The risk of perforation in the curved canal: Anticurvature filing compared with the stepback technique. Int Endod J. 1987;20(1):33-39.

24. Cunningham CJ, Senia ES. A three-dimensional study of canal curvatures in the mesial roots of mandibular molars. J Endod. 1992;18(6):294-300.

25. Harris SP, Bowles WR, Fok A, McClanahan SB. An anatomic investigation of the mandibular first molar using micro-computed tomography. J Endod. 2013;39(11):1374-1378.

26. GREEN D. Stereomicroscopic study of 700 root apices of maxillary and mandibular posterior teeth. Oral Surg Oral Med Oral Pathol. 1960;13:728-733. 
27. Shuping GB, Orstavik D, Sigurdsson A, Trope M. Reduction of intracanal bacteria using nickel-titanium rotary instrumentation and various medications. J Endod. 2000;26(12):751-755.

28. Buchanan LS. The standardized-taper root canal preparation--part 1. concepts for variably tapered shaping instruments. Int Endod J. 2000;33(6):516-529.

29. Chow TW. Mechanical effectiveness of root canal irrigation. J Endod. 1983;9(11):475-479.

30. Wilcox LR, Roskelley C, Sutton T. The relationship of root canal enlargement to fingerspreader induced vertical root fracture. J Endod. 1997;23(8):533-534.

31. Lertchirakarn V, Palamara JE, Messer HH. Patterns of vertical root fracture: Factors affecting stress distribution in the root canal. J Endod. 2003;29(8):523-528.

32. NICHOLLS E. Treatment of traumatic perforations of the pulp cavity. Oral Surg Oral Med Oral Pathol. 1962;15:603-612.

33. INGLE JI. A standardized endodontic technique utilizing newly designed instruments and filling materials. Oral Surg Oral Med Oral Pathol. 1961;14:83-91.

34. Kerekes K, Tronstad L. Long-term results of endodontic treatment performed with a standardized technique. J Endod. 1979;5(3):83-90.

35. Seltzer S, Bender IB, Smith J, Freedman I, Nazimov H. Endodontic failures--an analysis based on clinical, roentgenographic, and histologic findings. I. Oral Surg Oral Med Oral Pathol. 1967;23(4):500-516.

36. Sinai IH, Romea DJ, Glassman G, Morse DR, Fantasia J, Furst ML. An evaluation of tricalcium phosphate as a treatment for endodontic perforations. J Endod. 1989;15(9):399-403.

37. Farzaneh M, Abitbol S, Friedman S. Treatment outcome in endodontics: The toronto study. phases I and II: Orthograde retreatment. J Endod. 2004;30(9):627-633.

38. Zuckerman O, Katz A, Pilo R, Tamse A, Fuss Z. Residual dentin thickness in mesial roots of mandibular molars prepared with lightspeed rotary instruments and gates-glidden reamers. Oral Surg Oral Med Oral Pathol Oral Radiol Endod. 2003;96(3):351-355.

39. Stern N, Hirshfeld Z. Principles of preparing endodontically treated teeth for dowel and core restorations. J Prosthet Dent. 1973;30(2):162-165.

40. Johnson JK, Schwartz NL, Blackwell RT. Evaluation and restoration of endodontically treated posterior teeth. J Am Dent Assoc. 1976;93(3):597-605. 
41. Tilk MA, Lommel TJ, Gerstein H. A study of mandibular and maxillary root widths to determine dowel size. J Endod. 1979;5(3):79-82.

42. Caputo AA, Standlee JP. Pins and posts--why, when and how. Dent Clin North Am. 1976;20(2):299-311.

43. Gluskin AH, Radke RA, Frost SL, Watanabe LG. The mandibular incisor: Rethinking guidelines for post and core design. J Endod. 1995;21(1):33-37.

44. Sant'Anna Junior A, Cavenago BC, Ordinola-Zapata R, De-Deus G, Bramante CM, Duarte MA. The effect of larger apical preparations in the danger zone of lower molars prepared using the mtwo and reciproc systems. J Endod. 2014;40(11):1855-1859.

45. Schneider SW. A comparison of canal preparations in straight and curved root canals. Oral Surg Oral Med Oral Pathol. 1971;32(2):271-275.

46. Isom TL, Marshall JG, Baumgartner JC. Evaluation of root thickness in curved canals after flaring. J Endod. 1995;21(7):368-371.

47. Gutmann JL. The dentin-root complex: Anatomic and biologic considerations in restoring endodontically treated teeth. J Prosthet Dent. 1992;67(4):458-467.

48. Leseberg DA, Montgomery S. The effects of canal master, flex-R, and K-flex instrumentation on root canal configuration. J Endod. 1991;17(2):59-65.

49. Garcia Filho PF, Letra A, Menezes R, Carmo AM. Danger zone in mandibular molars before instrumentation: An in vitro study. J App/ Oral Sci. 2003;11(4):324-326.

50. Svec TA, Powers JM. The deterioration of rotary nickel-titanium files under controlled conditions. J Endod. 2002;28(2):105-107.

51. Koch KA, Brave DG. Real world endo sequence file. Dent Clin North Am. 2004;48(1):159-182.

52. Koch K, Brave D. The EndoSequence file: A guide to clinical use. Compend Contin Educ Dent. 2004;25(10A):811-813.

53. Garala M, Kuttler S, Hardigan P, Steiner-Carmi R, Dorn S. A comparison of the minimum canal wall thickness remaining following preparation using two nickel-titanium rotary systems. Int Endod J. 2003;36(9):636-642.

54. Grossman, L.I. Irrigation of root canals. The Journal of the American Dental Assassination, 1943;30(23):1915-1917. 
55. Muller, A.H. Morphology of root canals. Journal of the American Dental Association, 1936;23(9):1698-1706.

56. Ouzounian ZS. Remaining dentin thickness after endodontic cleaning and shaping before space preparation. Oral Health, 1991;81(13):5.

57. Gerstein H. Precision posts or dowel, III Dent J, 1963;32(70):3. 


\section{Appendix}

Preoperative mandibular mesial root curvature measurements

\begin{tabular}{|c|c|c|c|}
\hline & pre-op curvature degrees & & \\
\hline A1 & 15 & Group A (35) & \\
\hline A2 & 14 & Mean & 15.4 \\
\hline A3 & 17 & SD & 1.36 \\
\hline A4 & 14 & & \\
\hline A5 & 17 & & \\
\hline B1 & 20 & Group B (40) & \\
\hline B2 & 21 & Mean & 22.8 \\
\hline B3 & 35 & SD & 6.17 \\
\hline B4 & 20 & & \\
\hline B5 & 18 & & \\
\hline C1 & 22 & Group C (45) & \\
\hline C2 & 26 & Mean & 22.8 \\
\hline C3 & 20 & SD & 2.31 \\
\hline C4 & 21 & & \\
\hline C5 & 25 & & \\
\hline D1 & 25 & Group D (50) & \\
\hline D2 & 32 & Mean & 24 \\
\hline D3 & 15 & SD & 5.44 \\
\hline D4 & 25 & & \\
\hline D5 & 23 & & \\
\hline E1 & 22 & Group E (55) & \\
\hline E2 & 20 & Mean & 16.8 \\
\hline E3 & 11 & SD & 4.45 \\
\hline E4 & 19 & & \\
\hline \multirow[t]{4}{*}{ E5 } & 12 & & \\
\hline & & \multicolumn{2}{|l|}{ Entire Samples } \\
\hline & & Mean & 20.4 \\
\hline & & SD & 5.61 \\
\hline
\end{tabular}




\section{Group A (35.04)}
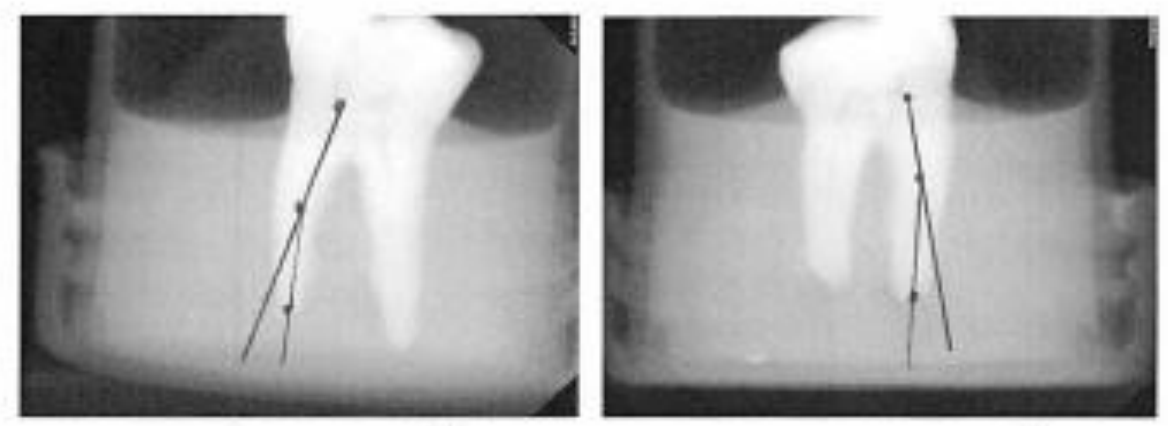

$$
\mathrm{A} 1\left(15^{\circ}\right)
$$
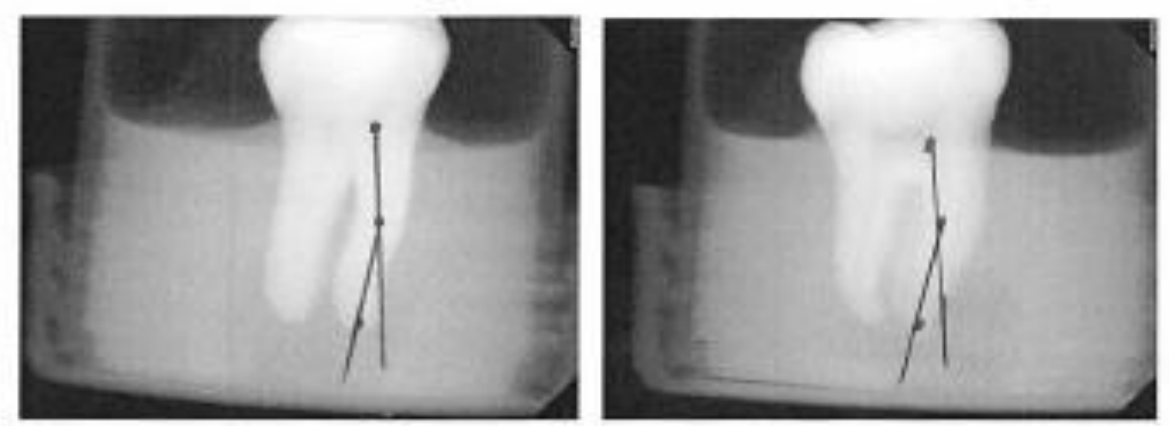

A3 $\left(17^{\circ}\right)$

A4 $\left(14^{\circ}\right)$

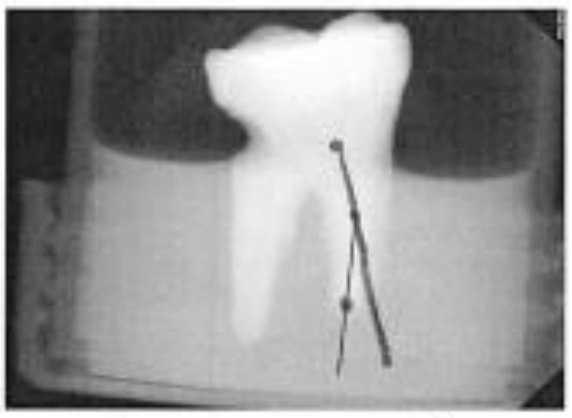

A5 $\left(17^{\circ}\right)$ 
Group B (40.04)
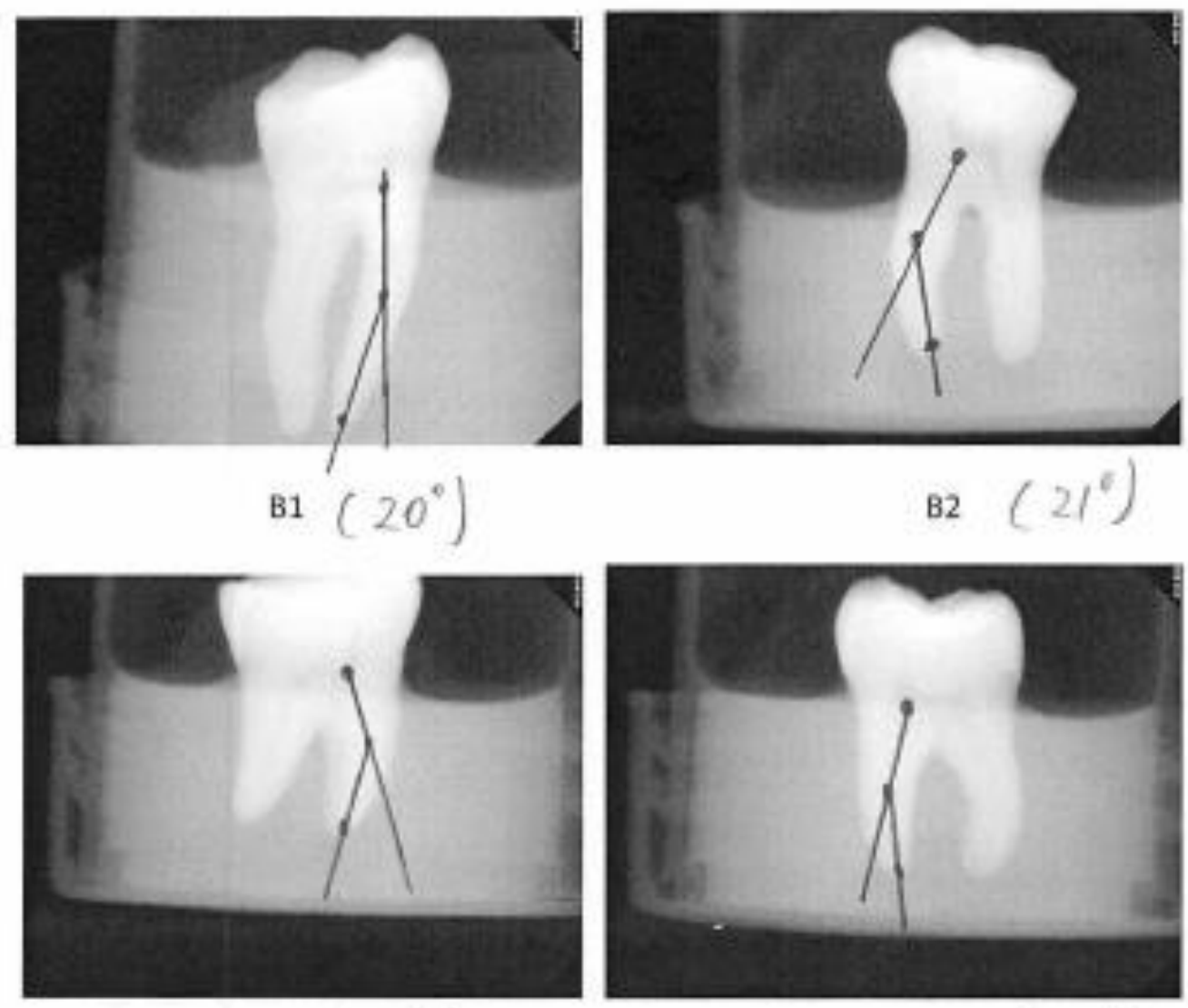

B3 $\left(35^{\circ}\right)$

$B 4\left(20^{\circ}\right)$

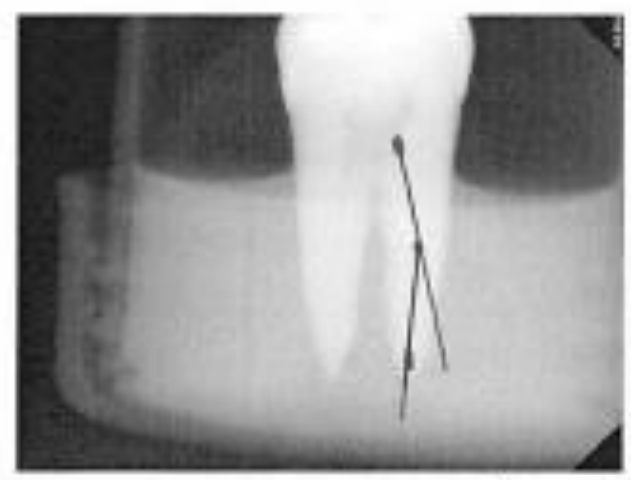

$85\left(18^{\circ}\right)$ 


\section{Group C (45.04)}
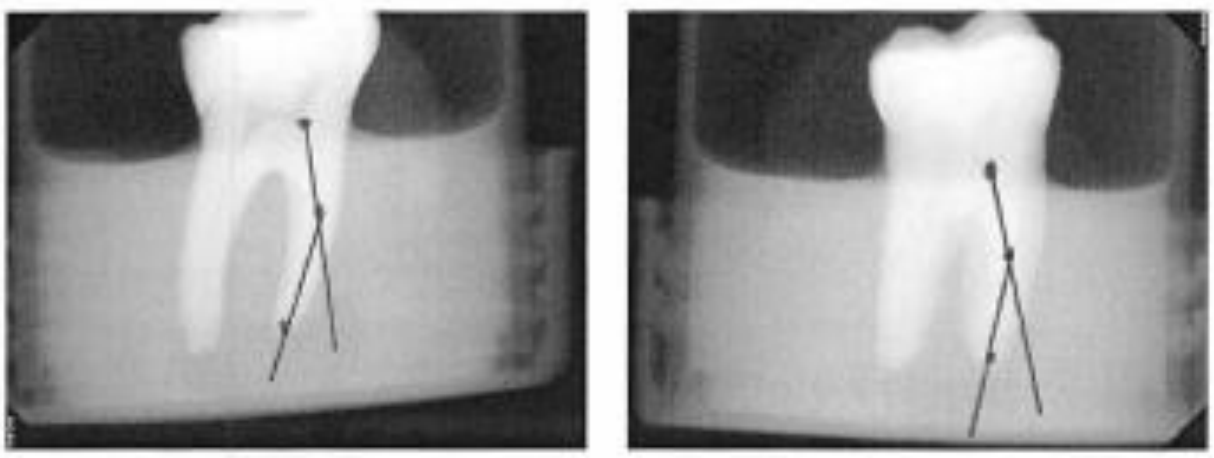

$\mathrm{C} 1\left(22^{\circ}\right)$

$c 2\left(26^{\circ}\right)$
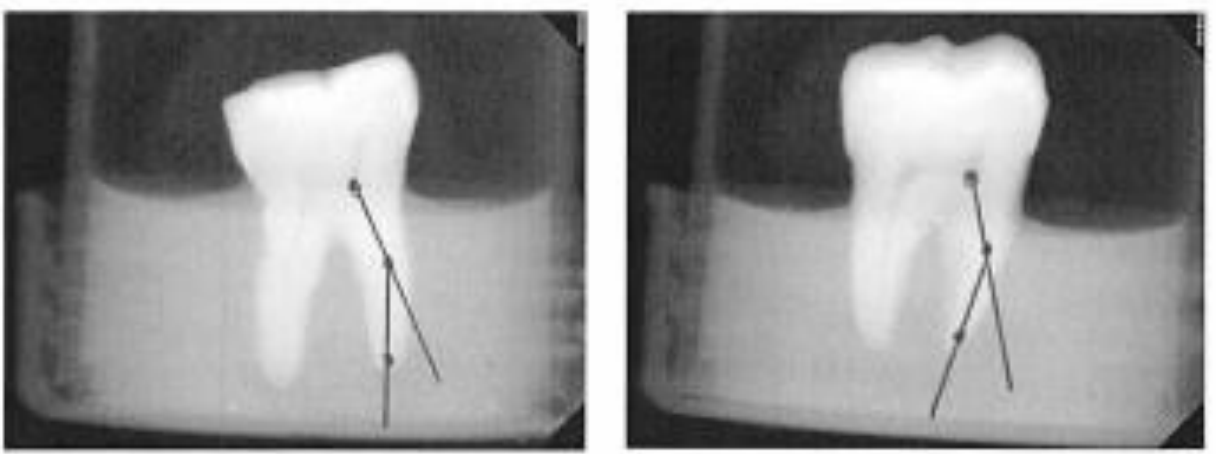

C3 $\left(20^{\circ}\right)$

$C 4\left(21^{\circ}\right)$

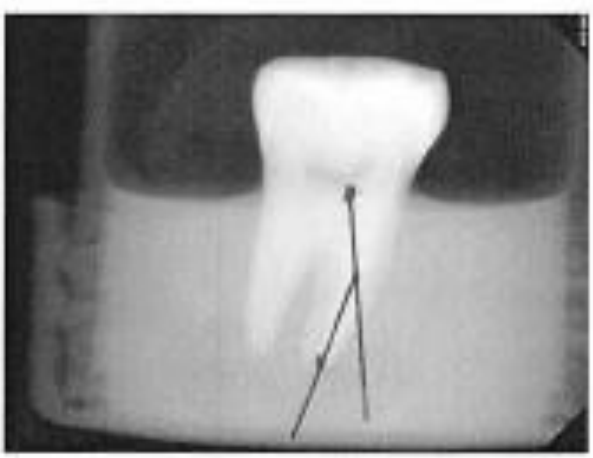

$\operatorname{c5}\left(25^{\circ}\right)$ 


\section{Group D (50.04)}
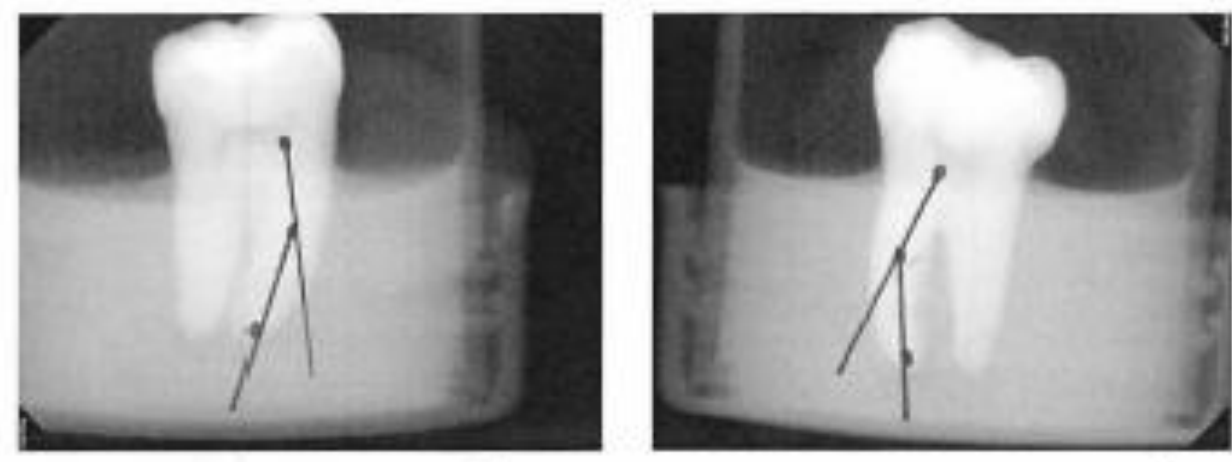

$$
\text { D1 }\left(25^{\circ}\right)
$$

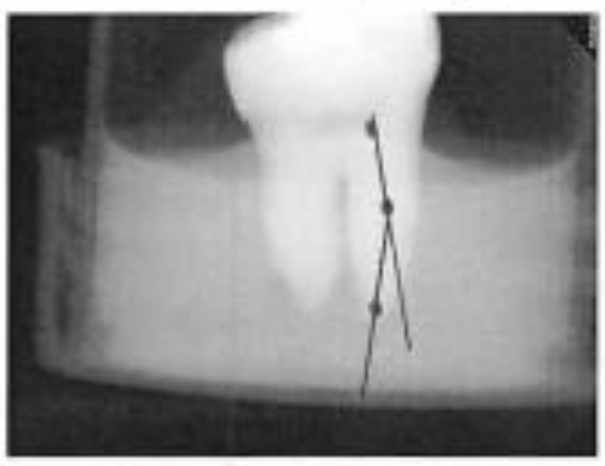

$$
{ }^{03}\left(15^{\circ}\right)
$$
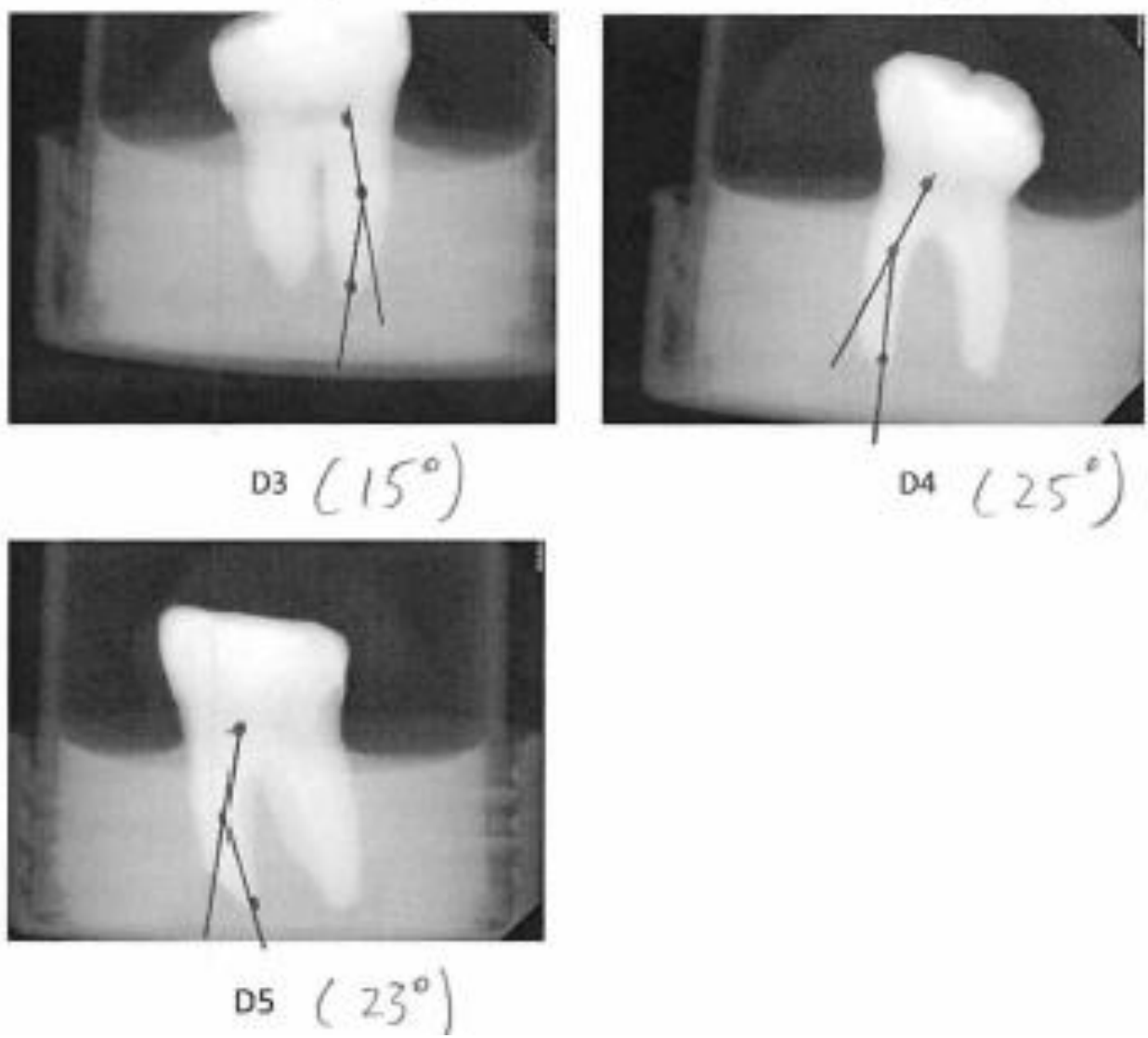

D4 $\left(25^{\circ}\right)$ 
Group E (55.04)
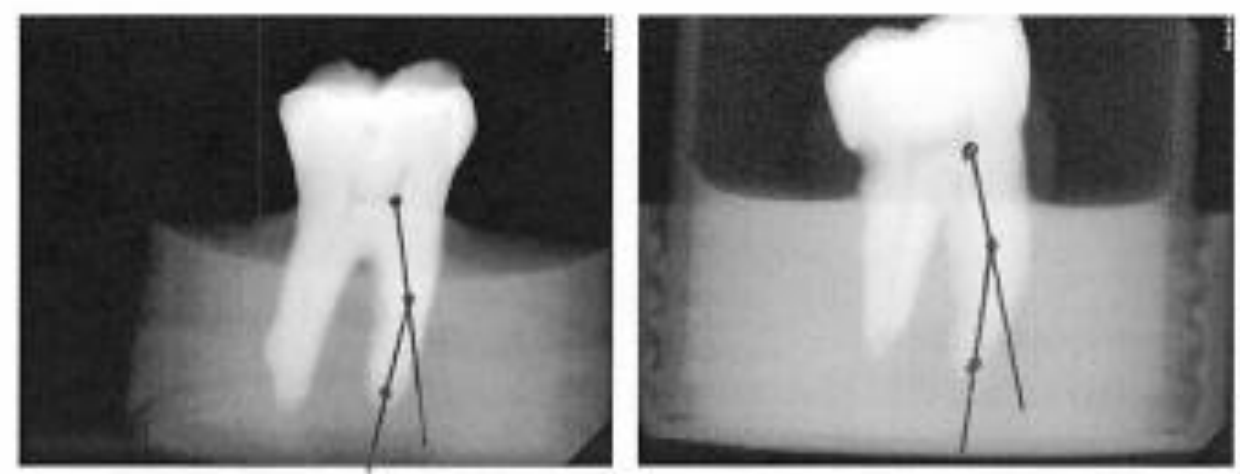

E1 $\left(22^{\circ}\right)$

E2 $\left(20^{\circ}\right)$
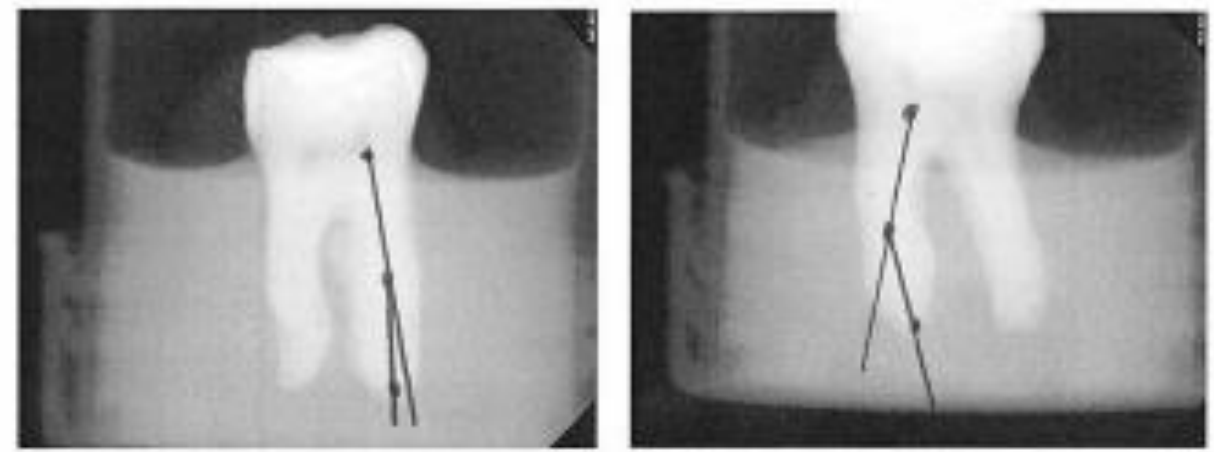

E3 $\left(11^{\circ}\right)$

E $\left(19^{\circ}\right)$

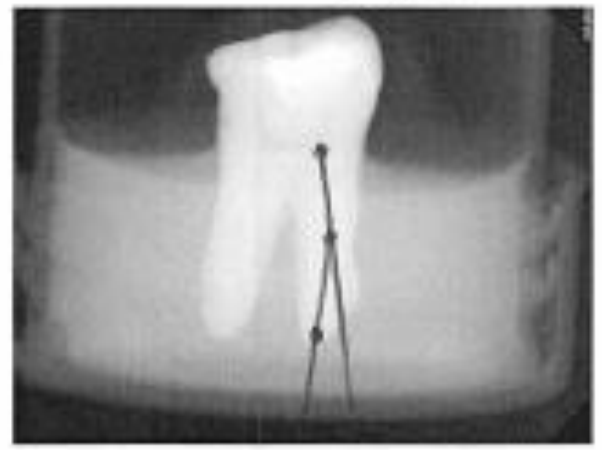

ES $\left(12^{\circ}\right)$ 


\section{Whest VurginiaUniversity. \\ Office of Research Integrity and Compliance}

\section{Acknowledgement Letter Not Human Subject Research NHSR}

To

From

Approval Period

Subject

Protocol Number

Title
Andrew Xu

WVU Office of Research Integrity and Compliance

06/02/2014 Expiration Date 06/01/2019

Not Human Subject Research Acknowledgment

1406315761

Residual dentin thickness on mandibular mesial dental root after shaping with niti rotary files assessing micro CT.

Thank you for your submission to the West Virginia University Institutional Review Board IRB.

It has been determined that your project does not meet the definition of human subject research for the following reasons

- $\quad$ This acknowledgement is under the understanding that these are de-identified collected extracted teeth. The researcher is randomly choosing from these collected teeth.

- $\quad$ Research means a systematic investigation designed to develop or contribute to generalizable knowledge. Most case reports and most oral histories are not generalizable and therefore not research. Many classroom projects if not intended to be published are also not considered research. Many quality improvement or program evaluation studies are not research.

- In order to be considered human subject research individually identifiable private information must be obtained or used in the research. If there is no individually identifiable private information involved the project is not human subject research and does not require being submitted to the Office of Research Integrity Compliance. Private information must be individually identifiable i.e. the identity of the subject is or may be readily ascertained by the investigator or someone else associated with the information in order to constitute research involving human subjects.

\section{If you have any questions, please contact the IRB at 3042937073.}

Thank you.

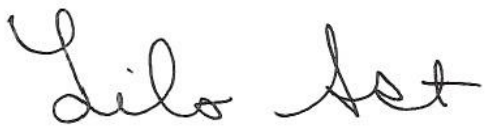

Board Designee Lilo Ast

Letter Sent By Lilo Ast on 06/02/2014 at 18:37:28-04:00 